This is the final peer-reviewed accepted manuscript of:

A Combined Approach Employing Chlorotoxin-Nanovectors and Low Dose Radiation To Reach Infiltrating Tumor Niches in Glioblastoma

Matteo Tamborini, Erica Locatelli, Marco Rasile, Ilaria Monaco, Simona Rodighiero, Irene Corradini, Mauro Comes Franchini, Lorena Passoni, and Michela Matteoli

ACS Nano 201610 (2), 2509-2520.

The final published version is available online at : http://dx.doi.org/10.1021/acsnano.5b07375

Rights / License:

The terms and conditions for the reuse of this version of the manuscript are specified in the publishing policy. For all terms of use and more information see the publisher's website.

This item was downloaded from IRIS Università di Bologna (https://cris.unibo.it/)

When citing, please refer to the published version. 
This document is confidential and is proprietary to the American Chemical Society and its authors. Do not copy or disclose without written permission. If you have received this item in error, notify the sender and delete all copies.

\section{A COMBINED APPROACH EMPLOING CHLOROTOXIN- NANOVECTORS AND LOW DOSE RADIATION TO REACH INFILTRATING TUMOR NICHES IN GLIOBLASTOMA}

\begin{tabular}{|r|l|}
\hline Journal: & ACS Nano \\
\hline Manuscript ID & nn-2015-07375s.R1 \\
\hline Manuscript Type: & Article \\
\hline Date Submitted by the Author: & n/a \\
\hline Complete List of Authors: & $\begin{array}{l}\text { Tamborini, Matteo; University of Milan, Department of Medical } \\
\text { Biotechnology and Translational Medicine } \\
\text { Locatelli, Erica; University of Bologna, Department of Industrial Chemistry } \\
\text { "Toso Montanari" } \\
\text { Rasile, Marco; University of Milan, Department of Medical Biotechnology } \\
\text { and Translational Medicine; Humanitas Clinical and Research Center, } \\
\text { Monaco, Ilaria; University of Bologna, Department of Industrial Chemistry } \\
\text { "Toso Montanari" } \\
\text { Rodighiero, Simona; Fondazione Filarete, } \\
\text { Corradini, Irene; University of Milan, Department of Medical Biotechnology } \\
\text { and Translational Medicine } \\
\text { Comes Franchini, Mauro; University of Bologna, Department of Industrial } \\
\text { Chemistry "Toso Montanari" } \\
\text { Passoni, Lorena; University of Milan, Department of Medical Biotechnology } \\
\text { and Translational Medicine; Fondazione Filarete, } \\
\text { Matteoli, Michela; Humanitas Clinical and Research Center, }\end{array}$ \\
\hline \hline
\end{tabular}

\section{SCHOLARONE}

Manuscripts 


\title{
A COMBINED APPROACH EMPLOING CHLOROTOXIN-NANOVECTORS AND LOW DOSE RADIATION TO REACH INFILTRATING TUMOR NICHES IN GLIOBLASTOMA
}

\author{
Matteo Tamborini ${ }^{\S}$, Erica Locatelli ${ }^{~ ", ~ M a r c o ~ R a s i l e ~}{ }^{\sharp}$, Ilaria Monaco ", Simona Rodighiero \\ ${ }^{*}$, Irene Corradini ${ }^{\S}$, Mauro Comes Franchini ${ }^{\Uparrow}$, Lorena Passoni ${ }^{\S}$, Michela Matteoli * \#
}

\begin{abstract}
Affiliations:
$\S$ Department of Medical Biotechnology and Translational Medicine, Via Vanvitelli 32, 20129 Milano, Italy

I Department of Industrial Chemistry "Toso Montanari”, University of Bologna, Viale Risorgimento 4, 40136 Bologna, Italy.

$¥$ Fondazione Filarete, Viale Ortles 22/4, 20139 Milano, Italy

\# Humanitas Research Hospital, Laboratory of Pharmacology and Brain Pathology, Via Manzoni 56, Rozzano, 20089 Milano, Italy

* CNR Institute of Neuroscience, Via Vanvitelli 32, 20129 Milano, Italy
\end{abstract}




\section{ASTRACT}

Glioblastoma multiforme (GBM) is the most aggressive form of glioma, with life expectancy of around two years after diagnosis, due to recidivism and to the blood brain barrier (BBB) limiting the amount of drugs which reach the residual malignant cells, thus contributing to the failure of chemotherapies. To bypass the obstacles imposed by the BBB we investigated the use of nanotechnologies combined with radiotherapy, as a potential therapeutic strategy for GBM. We used poly(lactic-co-glycolic acid) (PLGA) nanoparticles (PNP) conjugated to chlorotoxin (CTX), a peptide reported to bind selectively to glioma cells. Silver nanoparticles were entrapped inside the functionalized nanoparticles (Ag-PNP-CTX), to allow detection and quantification of the cellular uptake by confocal microscopy, both in vitro and in vivo. In vitro experiments performed with different human glioblastoma cell lines showed higher cytoplasmic uptake of Ag-PNP-CTX, with respect to non-functionalized nanoparticles. In vivo experiments showed that Ag-NP-CTX efficiently targets the tumor, but are scarcely effective in crossing the blood brain barrier in the healthy brain, where dispersed metastatic cells are present. We show here that a single whole brain x-rays irradiation, performed 20 hrs before nanoparticle injection, enhances the expression of the CTX targets, MMP-2 and CIC-3 and, through BBB permeabilization, potently increases the amount of internalized Ag-PNP-CTX even in dispersed cells, and generated an efficient anti-tumor synergistic effect able to inhibit in vivo tumor growth. Notably, the application of Ag-PNP-CTX to irradiated tumor cells decreases the extracellular activity of MMP-2. By targeting dispersed GBM cells and reducing MMP-2 activity, the combined use of CTX-nanovectors with radiotherapy may represent a promising therapeutic approach towards GBM.

KEYWORDS: glioblastoma, chlorotoxin-targeted nanovectors, drug delivery, ionizing radiation, MMP-2 
Glioblastoma (GBM) is the most common primary brain tumor, highly proliferative and invasive, characterized by remarkable biological heterogeneity and poor response to present treatments. ${ }^{1}$ Even when treated aggressively, GBM has the tendency to recur and this is the main cause of the poor prognosis. The area of recurrence develops at the borders of the surgical cavity, over $90 \%$ of the cases within $2 \mathrm{~cm}$ of the original tumor, or at distant sites within the brain at later stage. ${ }^{2}$ The median overall survival of GBM patients with the best currently available therapy is approximately 15 months, and the 5 -year survival rate is only $9.8 \%$ at present. $^{3}$

A major hurdle in the clinical management of GBM is the presence of the blood-brain barrier (BBB) which prevents pharmaceutical molecules entering the brain tissue. ${ }^{4,5}$ Large and advanced brain tumor exhibit disrupted BBB integrity. However peripheral areas of brain tumors contain regions with intact BBB leading to the creation of favorable niches of cancer cell spreading and treatment resistance. ${ }^{6}$ Thus, reaching dispersed and invading GBM cells remains a grand challenge for the successful treatment of GBM.

Given the intrinsic difficulty for most conventional drugs to reach the brain, the use of nanotechnological devices and nanoparticles has been suggested as an innovative therapeutic strategy. ${ }^{7}$ In particular, drug-loaded nanocarriers stably incorporating cytotoxic molecules have been proposed as promising tools. Indeed, nanovectors protect the drugs from metabolic degradation and fast clearance, prolonging circulation lifetime and thus ensuring a higher tumor delivery, reduce unwanted side effects and escape the efflux mechanisms determining tumor cell drug resistance. ${ }^{8,9}$

Due to their tunable characteristics, controlled- and sustained-release properties, biodegradability and biocompatibility, polymeric nanoparticles (PNPs) represent a powerful nanocarrier for the delivery of drug and/or diagnostic agents. Poly(lactic)-co-glycolic)-co-poly ethylene glycol (PLGA-bPEG) copolymer ${ }^{10}$ has gained large attention in the past decade, since its approval by Food and Drug Administration (FDA) for biomedical usage due to its ability to create micelles-like nanocarriers displaying an internal hydrophobic PLGA portion, suitable for entrapping lipophilic molecules, and an external hydrophilic PEG forming a stabilizing shell. ${ }^{11}$ However, PLGA nanoparticles, which are typically 100-200 nm in diameter, even when locally administered by convection-enhanced delivery (CED) have limited mobility and diffusion by convection through the brain interstitial spaces, ${ }^{12,13}$ which are $38-64 \mathrm{~nm}$ in normal brain ${ }^{14}$ and $70-100 \mathrm{~nm}$ in regions with tumor.$^{15}$ 
The presence of targeting ligands on surface of drug-loaded nanocarriers enhances tumor-specific intracellular uptake and drug accumulation, thus improving the nanovectors therapeutic efficacy. ${ }^{16}$ It has been reported that Chlorotoxin (CTX) can function as targeting moiety highly specific for GBM. ${ }^{17}$

CTX is a 36-amino acid peptide originally isolated from Leiurus quinquestriatus venom that specifically and selectively binds to glioma cells. ${ }^{17,18}$ Identified CTX target molecules are the matrix metalloproteinase-2 (MMP-2) ${ }^{19}$ and the chloride channel-3 (CIC-3) ${ }^{20}$ both absent in normal brain tissue but abundantly expressed in glioma cells. CIC-3 and MMP-2 form a protein complex which is targeted by the CTX-peptide, and thought to inhibit glioma cell invasion by induction of the endocytosis of the MMP-2/CIC-3 protein complex. ${ }^{19,21}$

Although CTX-coupled nanoparticles are considered a promising system for tumor treatment, isolated, infiltrating GBM tumor cells are hardly reached by functionalized nanoparticles, mostly due to the integrity of the BBB at the peripheral tumor sites. Given that ionizing radiations damage BBB integrity ${ }^{22,23}$ and induce MMP-2 expression, ${ }^{24-26}$ we hypothesized that they could enhance CTX-nanovectors, by increasing the CTX target expression and facilitating the nanovector brain penetration through BBB permeabilization. Also, we reasoned that, by promoting MMP-2 inhibition, application of CTX-nanoparticles could in turn limit tumor invasiveness, which is described to increase upon Radiation Therapy (RT). ${ }^{27,28}$ As RT represents one of the mainstays of GBM treatment, here we evaluated whether radiotherapy could benefit by the concomitant administration of CTX-targeted nanovectors and vice versa.

By intra-tumoral and intra-cellular quantification of CTX-targeted nanovectors we demonstrated that radiations, even at low doses, improve GBM tumor accumulation of CTX-nanovectors and are crucial to reach infiltrating and spreading tumor cells. The increased amount of CTX-nanovectors accumulated after radiation treatment within the tumor was sufficient to determine a detectable and significant reduction of tumor growth and MMP-2 enzymatic activity. Thus, the association of RT with the use of CTX-functionalized drug-loaded nanovectors appears to represent a promising strategy for GBM treatment. 


\section{RESULTS AND DISCUSSION}

\section{Synthesis and Characterization of Ag-PNP-CTX nanovectors}

With the intent to quantify chlorotoxin (CTX)-targeted nanovectors reaching the tumor microenvironment, and to track their localization into intracellular compartments, we synthesized poly (lactic)-co-glycolic)-co-poly ethylene glycol (PLGA-b-PEG) nanovectors conjugated to CTX and encapsulating silver nanoparticles (Ag-nps), visible with optical microscope imaging in reflection mode ( Ag-PNP-CTX).

Ag-PNP-CTX were prepared following a procedure already reported by us (Figure $1 \mathrm{~A}$ ). ${ }^{29}$ Firstly, Ag-nps were obtained through reduction of $\mathrm{AgNO}_{3}$ by glucose and $\mathrm{NaOH}$ in presence of polyvinylpyrrolidone (PVP) and later they were coated with the organic ligand 1 in order to obtain lipophilic nanoparticles (Ag-nps-1). ${ }^{30}$ Native Ag-nps present a hydrodynamic diameter of $35.4 \pm 5.3$ $\mathrm{nm}$, which increased to $40 \pm 7.6 \mathrm{~nm}$ after the coating with the organic ligand. A complete characterization of Ag-nps-1 was previously reported. ${ }^{31}$ Ag-nps-1 were then entrapped into PLGAPEG polymeric nanoparticles (PNP). The nanoprecipitation method was exploited for this purpose and led to the entrapped of Ag-nps-1 in the inner core of the water-soluble PNP. Ag-PNP were then chemically conjugated onto the outer shell with the specific targeting agent CTX, thus giving Ag-PNP-CTX. For this reaction the presence of carboxylic acid groups, derived from PEG chains, onto the surface of Ag-PNP was exploited for the formation of an amide bond with free-amino ending group of CTX.

Ag-PNP-CTX were characterized by Transmission Electron Microscopy (TEM, Figure 1 B). Dynamic light scattering (DLS) revealed particles with diameter equal to $114 \pm 2 \mathrm{~nm}$, a low polydispersity index (PDI) $(0.21 \pm 0.01)$ and a negative $\zeta$-potential $(-31.6 \mathrm{mV})$. Silver concentration was determined to be $3.81 \mathrm{mM}$ by means of atomic absorption spectroscopy (AAS). The overall Ag-PNP-CTX concentration was established by gravimetric analysis and found to be $8.87 \mathrm{mg} / \mathrm{mL}$.

\section{Optical imaging and quantification, and in vivo biodistribution of encapsulated Ag-nps}

A key issue to achieve therapeutic efficacy resides in the amount of nanovectors that localize at the tumor site, and are internalized into the tumor cells. This is particularly relevant for GBM which is a high infiltrating and metastatic tumor, hardly accessible due to the presence of the BBB. Therefore, the use of accurate and quantitative methods to track systemically injected nanovectors is of crucial importance to evaluate and foresee their potential therapeutic efficacy. 
Taking advantage of the high contrast provided by Ag-nps, we explored Ag-nps as contrast agents for optical microscopy detection and imaging of PNPs without the need to add fluorescent dyes, thus avoiding chemical modification of the outer shell of the nanocarriers, which can modify PNP behavior inside the body. First, the intracellular quantification of Ag-nps contained into PNPs nanovectors was performed in human GBM-derived cell lines by confocal microscopy. Pictures of the nanoparticles alone by reflectance mode imaging are shown in Figure $2 \mathrm{C}-\mathrm{E}$. As hypothesized, intracellular localization and quantification of Ag-nps turned out to be a feasible procedure (Figure 2 A, B, F-I). Results showed that conjugation with CTX significantly increases the intracellular accumulation of Ag-nps in GBM cells as shown by comparison between Ag-PNP-CTX and Ag-PNP nanocarriers (Figure $2 \mathrm{~L}$ ). A competition assay, performed by pretreating GBM cells with increasing concentrations of native CTX peptide, indicated a significantly lower, dose-dependent, uptake of targeted Ag-PNP-CTX. The CTX peptide did not modify the uptake of non-targeted Ag-PNP nanovector (Figure $2 \mathrm{M}$ ). Furthermore, in agreement with the described capacity of PLGA nanovectors to undergo endosomal escape, ${ }^{32-34}$ the intracellular trafficking analysis showed no co-localization of Ag-nps with endosomal and lysosomal fluorescent markers (Figure $1 \mathrm{~N}$ ) implying that CTX-nanovector cargo would be entirely released into the cytoplasm and not sequestered and/or degraded inside cellular organelles.

Ag-nps proved to be a suitable tool also upon biodistribution evaluation in peripheral organs. After Ag-PNP-CTX intra peritoneal (i.p.) injection, animals were sacrificed at selected time points and different tissues including liver, spleen, lung, heart and kidney were collected and examined for the presence of Ag-nps by Inductively Coupled Plasma Mass Spectrometry (ICP-MS). As expected the majority of Ag-PNP-CTX accumulated in the RES organs (liver, $\sim 80 \%$, and spleen, $\sim 4 \%$ of the injected Ag-nps). Only $2 \%$ of injected Ag-nps accumulated in the lung and a noteworthy nanoparticles washout was observed at 48 hours from nanovector administration. Barely no AgPNP-CTX nanovectors accumulate in the heart and in the kidney (Supplementary Figure 1).

Thus Ag-nps appear to represent a valuable imaging tool for single-cell analysis, endowed with superior quality and precision with respect to standard fluorescence due to the high stability and the absence of photobleaching of Ag-nps. Indeed, the light reflection property of Ag-nps allows the acquisition of Ag-nps signal in reflection mode, without affecting the freedom of choice of fluorescent labeled when the localization of diverse proteins have to be studied in multicolor experiments. Moreover a fluorescent moiety, linked or adsorbed onto the external surface, may undergo leakage phenomena from the nanosystem once in the body environment, which can lead in turn to unspecific fluorescence detection in not really targeted cells; on the contrary, Ag-nps being strongly entrapped inside the polymeric matrix, are stable and not subjected to this 
inconvenience. As a general rule, the use of Ag-nps-loaded nanovectors may represent a valuable tool to measure the delivery potential and/or to define the proper administration route and scheduling of drug-loaded nanovectors of interest.

\section{Radiations Boost CTX-targeted nanovector accumulation in GBM tumors}

To verify the possibility to exploit Ag-PNP-CTX in vivo, the amount of Ag-nps accumulating into the tumor and the healthy brain parenchyma was evaluated in an orthotopic mouse model of human GBM (Figure 3) receiving Ag-PNP-CTX by systemic administration (i.p.). U87MG cells were inoculated into the right hemisphere via stereotactic techniques. The GBM-tumor area was defined by immunohistochemical staining for human nestin, a staminal marker overexpressed in glioma stem cells ${ }^{35}$ (Figure 3 A). Importantly, the U87MG orthotopic tumor was able to originate infiltrative tumor niches. Indeed, in addition to the main tumor mass, groups of nestin-positive infiltrating cells were detectable within the healthy parenchyma at the periphery of the tumor (Figure $3 \mathrm{~B}$ and $\mathrm{C}$ ). Outstandingly, we were able to detect single tumor cells spread into healthy tissue (Figure $3 \mathrm{C}$ ), thus increasing the translational relevance of our studies.

Ag-nps detection and quantification inside the tumor was performed by confocal microscopy imaging on brain cryosections. Ag-nps quantification showed a significant higher level of accumulation in the GBM-tumor compared to healthy brain parenchyma where nearly no Ag-nps were detected (Figure 4, 0 Gy). However, despite CTX favors Ag-PNP-CTX nanovector internalization into GBM cells, CTX is not an agent for BBB crossing, thus nanovector brain biodistribution could be limited by the presence of this barrier. Considering that RT is a mainstay of GBM therapy regimens ${ }^{2,3}$ and that radiations affect BBB permeability, ${ }^{22,23}$ the consequence of a radiation treatment on Ag-PNP-CTX nanovector tumor accumulation was assessed. To adhere with current clinical protocol of RT used to treat GBM patients (60 Gy delivered in fractions of 2 Gy

${ }^{2}$ ) we chose 2 Gy as a standard experimental RT dosage (Figure 4 A and Supplementary Figure 2). Interestingly, a further, substantially increased amount (4 to 6 folds) of Ag-nps was detectable in GBM-tumors subjected to radiations compared to the absence of the radiations. A higher quantity of Ag-nps was observed 48 hours from Ag-PNP-CTX injection compared to 24 hours suggestive of an enhanced permeability and retention (EPR) effect, possibly preventing nanovectors wash out and facilitating their accumulation (Figure 4). Noteworthy, radiation treatment did not determine an increased accumulation of Ag-nps in healthy brain parenchyma (Figure 4B). 


\section{Radiations alter the blood-brain barrier allowing the targeting of GBM cells infiltrating healthy brain parenchyma}

We next aimed to assess whether the lack of Ag-nps in the irradiated brain healthy parenchyma was due to the presence of an intact BBB and to investigate the contribution of BBB integrity in the enhanced accumulation of Ag-PNP-CTX nanovectors in GBM tumors observed upon radiation treatment. To this aim we performed immunostaing for Claudin-5, one of the highly expressed brain endothelial tight junction proteins contributing in maintainance of BBB integrity. ${ }^{36}$ Claudin- 5 levels and pattern of expression were determined by immunohistochemistry on cryosections from normal and U87MG-implanted brain hemispheres treated and non-treated with radiations. Results indicated that a single dose of 2 Gy radiation caused alterations in claudin- 5 distribution pattern, which was particularly evident in the healthy brain where the formation of gaps in brain vessel wall, caused by the opening of the tight junctions was clearly detectable (Figure $5 \mathrm{~A}$ and $\mathrm{B}$, see also 3D reconstructions). Differently from healthy brain, the tumorigenic GBM microenvironment promotes neo-angiogenesis and disruption of BBB integrity (Figure $5 \mathrm{C}$ and data not shown). ${ }^{37}$ The permeabilization of the BBB in the tumor area allows in fact penetration and retention of Ag-nps within the non-irradiated GBM-tumor, although at a lesser extent compared to the irradiated one (Figure 4).

While the integrity of the BBB would guarantee reduced nanovectors off-target brain toxicity, it makes infiltrating and metastatic GBM cells inaccessible to nanovectors. Indeed, in the proximity of the peripheral zone of the tumor we observed a normal claudin- 5 expression, suggestive of an intact BBB (Figure $5 \mathrm{D}$ ). We therefore focused on the tumor periphery in order to investigate the penetration of Ag-nps in dispersed cancer cells located far from the tumor mass, identified by their immunoreactivity to antibodies directed against human nestin. As expected, no Ag-nps accumulation in nestin-positive cells (Figure $5 \mathrm{E}$, left panel and Supplementary Figure 3). After 2 Gy radiation treatment, however, in line with BBB permeabilization, Ag-nps could be detected in the isolated GBM cells branching into the healthy parenchyma (Fig $5 \mathrm{E}$, right panel and Supplementary Figure 3).

Despite low doses of radiations were enough to determine in vivo tight junction opening (Figure 5B), the presence of a compromised BBB didn't allow significant accumulation of Ag-nps in irradiated healthy brain parenchyma (Figure 4). This is consistent with the presence, in the proximity and surrounding the brain vessels, of pericytes and astrocytes that contribute hindering the passive passage of nanovectors. ${ }^{38}$ Furthermore, the interstitial fluid pressure ${ }^{39}$ and the width of the extracellular space impact on nanovector access and penetration within the healthy parenchyma. It was previously reported that the extracellular spaces in normal brain are between 
38 and $64 \mathrm{~nm} .{ }^{14}$ Therefore, 100nm-sized CTX-nanovectors, likewise the ones used in this study, would hardly diffuse and accumulate in healthy brain tissue. It is conceivable that ECM components would physically restrict the motion of nanovector in convection through the extracellular space.

\section{Radiation Augments Specific Cellular Uptake and Intracellular Localization by inducing MMP-2 and CIC-3 overexpression}

The presence of ligands on nanocarrier surface increases the active intracellular uptake determining higher payload delivery inside the cells. ${ }^{16}$ Notably, while irradiated cells, both U87MG and T98G lines, incubated in the presence of Ag-PNP-CTX displayed a significant increase in intracellular Ag-nps, no variations were observed in either cell lines when incubated in the presence of non-targeted Ag-PNP nanovectors (Figure 6A and 6B). Given CTX is the ligand for MMP-2 and CIC-3, which are highly expressed in human gliomas, ${ }^{17,21}$ we quantified the expression of these molecules in irradiated tumor, compared with the not irradiated ones. RT is known to induce MMP-2 expression ${ }^{24-26}$ but no data are available yet on CIC-3 expression after radiation treatment.

Our data indicated that up-regulation of MMP-2 and CIC-3 levels of expression is induced by radiations, as assessed by western-blot analysis (Figure 6B). The effect was particularly evident for CIC-3. Similarly, simultaneous microscopy detection of MMP-2 or CIC-3 and Ag-nps in nonirradiated and irradiated U87MG cells confirmed that radiations increase MMP-2 and CIC-3 levels of expression, which correlate with a higher amount of internalized Ag-nps (Figure 6C and D, Supplementary Figure 4). Notably, the increased expression of MMP-2 and CIC-3 was observed also in vivo, in irradiated U87MG xenografts (Figure 7). Despite the results obtained in vitro indicated a noteworthy increase of CIC-3 expression compared to MMP-2 after radiation treatment, the in vivo $\mathrm{ClC}-3$ and MMP-2 levels were comparable, thus suggesting an equivalent contribution for nanovectors cellular uptake and internalization.

The lack of Ag-nps accumulation in infiltrating GBM cells in the absence of radiation treatment (Figure $5 \mathrm{E}$ ) is compatible with the possibility that, besides favoring permeabilization of the BBB, ionizing radiations, by enhancing the expression of cellular proteases, including MMP-2, play a crucial role in degradation and remodeling of brain extra cellular matrix (ECM) thereby facilitating extravasation, convective movements and diffusion of CTX-nanovectors. This is relevant in the clinical setting, where RT is applied not only to the tumor area but extended to a $2 \mathrm{~cm}$ surrounding margins where invading GBM stem-like cells escape to surgery and survive to RT. ${ }^{40,41}$ Thus the 
concomitant use of CTX-nanovectors during RT should facilitate and enhance drug-delivery to the invading and metastatic GBM stem-like cells that are the responsible for the majority of the recurrences.

\section{CTX-targeted nanovectors function as inhibitor of MMP-2 enzymatic activity}

MMP-2 belongs to a family of endopeptidases, which can cleave almost every component of the ECM proteins. ECM degradation is a key event in the progression, invasion, and metastasis of malignant lesions. ${ }^{42}$ Notably, increase of metastatic tumor activity has been described as a consequence of RT, which enhances MMP-2 expression. ${ }^{25}$ We therefore asked whether the binding of CTX-nanovectors to MMP-2 could interfere with its catalytic activity. MMP-2 activity was evaluated by zimography in irradiated U87MG cells incubated with non-targeted Ag-PNP and targeted Ag-PNP-CTX nanovectors. Remarkably, MMP-2 catalytic activity was inhibited of about $50 \%$ exclusively in cells incubated with targeted Ag-PNP-CTX nanovectors while no changes were observed in irradiated cells incubated with non-targeted Ag-PNP nanovectors (Figure 8). Thus, CTX-PNP nanovectors could attain synergistic dual therapeutic effects, tumor-specific intracellular drug-delivery and inhibition of MMP-2 activity. Interestingly, it has been demonstrated that inhibition of MMPs, including MMP-2, provides a potential strategy for improving RT efficacy. ${ }^{27,28}$

\section{Radiations enhance Ag-PNP-CTX cytotoxic activity against U87MG GBM cells}

Recently the possibility to use Ag-nps as anticancer agents for GBM, either alone ${ }^{29,43}$ or in combination with other drugs, ${ }^{31}$ after entrapment in biocompatible PNPs has been explored. Hence, the effect of a combined administration of 2 Gy radiation treatment and Ag-PNP-CTX on U87MG cell growth and viability was investigated.

Irradiated and non-irradiated U87MG cells were incubated with different concentrations of Ag-PNPCTX nanovectors for 72 hours and, at the end of the treatment period, cell viability was assessed by MTT test. Parallel U87MG cells were treated with either nanovectors without Ag-nps (PNPCTX), for polymer and CTX toxicity assessment, or non-targeted nanovectors (Ag-PNP), as control for specific uptake. As expected, no cellular toxicity was observed by incubating U87MG cells with empty PNP-CTX nanovectors, while the presence of CTX on the surface of Ag-PNP nanovectors triggered a dose-dependent cell growth inhibition induced by the encapsulated Ag-nps. More interestingly, a synergic reduction of U87MG cell viability was observed when combined treatments, radiations (2 Gy) and Ag-PNP-CTX nanovectors, were applied (Figure 9A). Proapoptotic synergic effect was confirmed in vivo in U87MG-transplanted mice. The detection and 
quantification of apoptotic bodies by in situ terminal deoxynucleotidyltransferasedUTP nick end labeling (TUNEL) assay indicated a significant apoptosis increase in irradiated U87MG xenografts exposed to radiations and Ag-PNP-CTX nanovectors vs. U87MG xenografts treated with CTX nanovectors or exposed to radiations as single agents (Figure 9B).

Corroboration of the TUNEL results was provided by bioluminescence imaging (BLI) analysis performed in luciferase-transfected U87MG (U87MGluc2) xenografts to monitor tumor growth over the treatment period (Figure $9 \mathrm{C}$ and $\mathrm{D}$ ). Eleven days post U87MGluc2 cells implantation $(\mathrm{T}=0)$, when the tumor mass was detectable by BLI, mice were divided into 4 groups: untreated mice; mice treated with radiations (2Gy, single dose); mice treated with serial injections of Ag-PNP-CTX single agent ( 2 doses of $1 \mathrm{mg}$ dry matter / mouse, followed by 2 doses of $0,5 \mathrm{mg}$ dry matter / mouse; interval time: 48-72 hours); mice treated with radiations and Ag-PNP-CTX concomitantly.

As illustrated in Figure 9C, showing representative images of single animals from each experimental group, and 9D, showing the quantitative analysis of the tumor areas, combined radiations and CTX-nanovectors treatment inhibited tumor growth and progression. No inhibitory effect was observed in mice treated with either radiations or Ag-PNP-CTX alone.

The observed increased level of apoptosis together with the in vivo inhibition of tumor growth would suggest a positive anti-tumor effect of Ag-nps. Though, more meaningfully, the positive results obtained with Ag-PNP-CTX provide the proof-of-concept of the therapeutic validity of a combination strategy based on radiation therapy and CTX-targeted polymeric nanovectors, which is expected to strengthen the anti-tumor efficacy of any cytotoxic molecules entrapped into PNPCTX nanovectors.

\section{CONCLUSIONS}

In this report, we described a nanotechnological strategy for the treatment of GBM that addresses two relevant obstacles to effective therapy: 1) the infiltrative nature of GBM; 2) the increase in MMP-2 expression following radiotherapy. Overall our results showed that (i) although large and advanced GBM tumors disrupt the BBB sufficiently to allow extravasation of engineered nanocarriers, low dose RT (2 Gy, single dose), by inducing overexpression of proteases such as MMP-2, which also represent CTX molecular targets together with the chloride channel CIC-3, render tumor ECM more porous and permeable to nanovectors, determining their significant enhanced accumulation; ii) differently from the main tumor mass, peripheral GBM tumor niches, where more tumorigenic and invading cells reside, are accessible to engineered nanocarriers 
exclusively upon radiation treatment; iii) low dose RT is not enough to determine complete BBB disruption preventing nanocarrier accumulation in irradiated healthy brain parenchyma; iv) CTX surface functionalization, besides causing an increased cellular uptake of CTX-targeted nanovectors, inhibits MMP-2 enzymatic activity.

Furthermore, silver nanoparticles proved to represent a valuable imaging tool for single-cell analysis both in vitro and in vivo, with superior quality and precision respect to standard fluorescence. Indeed, Ag-nps were of fundamental importance to demonstrate nanovector localization in vivo in peripheral infiltrating GBM tumor niches.

Having demonstrated that an increased nanovectors accumulation and retention can be achieved at significant lower dose of RT (2 Gy), we provide a strong and relevant rationale for the development of therapeutic strategies able to target tumorigenic and invading GBM cells based on the concomitant administration of RT and CTX-targeted nanovectors. A synergistic therapeutic effect could start from the first fractionated RT dose. Considering that radiations induce the expression of molecules such as MMPs that favor tumor invasion and metastases, the concomitant administration of RT and CTX-targeted nanovectors could represent a significant step forward to GBM management. Indeed, the synergistic effect of CTX-targeted would result from a significant increased accumulation of nanovector therapeutic cargo inside GBM cells and from the inhibition of approximately $50 \%$.of MMP-2 catalytic activity. Thus we conclude that CTX-targeted nanovectors as adjuvants to RT may increase the efficacy of anti-GBM therapies. 


\section{METHODS}

Synthesis and characterization of Ag-PNP-CTX nanovectors. $100 \mathrm{mg}$ of PLGA-b-PEG$\mathrm{COOH}(7 \mathrm{kDa}-3 \mathrm{kDa})$ and AgNPs-1, both prepared as already reported ${ }^{30}$, were admixed into 10 $\mathrm{mL}$ of dimethylformamide (DMF). This organic phase was mixed with $100 \mathrm{~mL}$ of ultrapure water under vigorous stirring, maintaining water/organic ratio 10/1 with a constant removal of the solution. The mixture was kept for $30 \mathrm{~min}$. under vigorous stirring then washed and concentrated by using centrifugal filter devices (Amicon Ultra, Ultracell membrane with 100.000 NMWL, Millipore, USA) to a final volume of $5 \mathrm{~mL}$ and finally filtered by using a syringe filters phenex-PES of polyether sulfone ( $26 \mathrm{~mm}, 0.20 \mu \mathrm{m}$, Phenomenex, Italy). To a suspension of the so obtained AgPNP $(5 \mathrm{~mL})$ in PBS $(10 \mathrm{~mL}, 0.01 \mathrm{M})$, under magnetic stirring, a solution of $\mathrm{N}$ hydroxysulfosuccinimide $2.3 \mathrm{mM}(8.7 \mathrm{~mL})$ and a solution of 1-ethyl-3-(3-dimethylaminopropyl) carbodiimide $0.28 \mathrm{M}(3.6 \mathrm{~mL})$ was added. The reaction was carried out at room temperature for 15 minutes then $50 \mu \mathrm{g}$ of Chlorotoxin, dissolved into $1 \mathrm{~mL}$ of water, were added and left to react for 24 hours. After that Ag-PNP-CTX were purified and concentrated to a final volume of $5 \mathrm{~mL}$ as previously described. Dynamic light scattering (DLS) analysis and $\zeta$-potential values were obtained with a Zetasizer Nano-S (Malvern) instrument, working with a $532 \mathrm{~nm}$ laser beam at $25{ }^{\circ} \mathrm{C}$, using standard cuvettes or DTS1060C Clear Disposable zeta cells, and the results expressed as average of three measurements. Atomic absorption analysis was conducted in a SpectraAA 100 Varian instrument, with opportune AgNO3 standards for calibration line. Final concentration of the suspensions was determined by gravimetric analysis by drying $100 \mu \mathrm{L}$ of solution at $130{ }^{\circ} \mathrm{C}$ for 24 hours then accurately weighting the residual dry matter amount.

Cell Culture. Human-derived GBM cell line were grown in Minimum Essential Medium Eagle, Alpha Modification ( $\alpha$ MEM) (U87MG) or RPMI (A172, T98G) (Lonza, Basel, Switzerland) supplemented with $10 \%$ fetal calf serum (FCS, U.S. Origin, Gibco/Life Technologies), $100 \mathrm{U} / \mathrm{ml}$ penicillin and $0,1 \mathrm{mg} / \mathrm{ml}$ streptomycin. Cells were mantained at $37^{\circ} \mathrm{C}$ in a humidified incubator with $5 \% \mathrm{CO}_{2}$.

Competitive inhibition assay. U87MG and A172 cell lines were pre-treated for 2 hours with decreasing concentrations of the native CTX peptide (MCMPCFTTDHQMARKCDDCCGGKGRGKCYGPQCLCR-NH ${ }_{2}$ ) (H6086, Bachem, Bubendorf, Switzerland) followed by incubation with targeted (Ag-PNP-CTX) or non-targeted (Ag-PNP) nanovectors at $\mathrm{Ag}$ concentration of $100 \mu \mathrm{M}$ for 16-18 hours (overnight). The intracellular accumulation of $\mathrm{Ag}$ nanoparticles (Ag-nps) was determined by confocal laser scanning microsco and 3D imaging analysis performed by IMARIS software (see below). 
Mouse orthotopic xenografts. Mouse experiments were carried out according to the protocol approved by Italian Minister of Health (protocol number 171/2013-B). CD-1 male nude mice, 6-8 weeks (Charles Rivers Laboratories, Calco, Italy) were housed in specific pathogen free animal house. Sterilized Water and rodent chow were given ad libitum. Mice were injected intracranially into the right striatum with U87MG cells at $5 \times 10^{4}$ cells/mouse or luciferase-transfected U87MGluc2 (gently provided by Laura Cerchia, CNR Naples, Italy) $10^{5}$ cells/mouse. For intratumor nanovector accumulation analysis and quantification, U87MG-tumors were allowed to grow for 15 days, and then mice were subject to whole-brain single dose radiation (2 Gy). Ag-PNP-CTX were administered intraperitoneally at a dose of $1 \mathrm{mg}$ of dry matter 18 hours after radiations. Animals were euthanized 24 or 48 hours after nanovector injection. For immunofluorescence experiments intracardiac perfusion was carried out with 4\% PFA. The harvested brains and organs were frozen and conserve at $-80^{\circ} \mathrm{C}$.

To study the antitumor effect of Ag-PNP-CTX, U87MGluc2-tumors were allowed to growth for 11 days, and then mice were randomized and divided in 4 groups: not treated animals (controls), animal treated only with Ag-PNP-CTX nanovectors, animal treated only with radiations, and animal treated with radiations and Ag-PNP-CTX nanovectors. Mice were subject to wholebrain single dose radiation (2 Gy, T0). Ag-PNP-CTX administration started 18 hours after radiation treatment. Mice received 4 consecutive doses of Ag-PNP-CTX nanovectors (first 2 doses: $1 \mathrm{mg}$ of dry matter; third and fourth doses: $0,5 \mathrm{mg}$ of dry matter) at intervals of $48-72$ hours.

In vivo imaging of intracranial tumors. An IVIS II Imaging System (Caliper LifeScincesPerkin Elmer-Waltham, Massachusetts, USA) was used to take photograph and luminescent images setting an open filter and binning 8. Exposure time was fixed at 1 minute and 5-10 images were acquired until maximum photon flux achievement. Ten minutes before acquisition, mice were administered intraperitoneal injection of D-luciferin (Perkin Elmer-Waltham), $150 \mathrm{mg} / \mathrm{Kg}$, as a substrate for the luciferase enzyme. Images were captured and quantified with Living Image 4.3.1 software (Perkin Elmer-Waltham), based on equivalent regions of interest over the head. Analysis was carried out using the Living imaging software (Perkin Elmer - Waltham, Massachusetts, USA) setting binning 4 and "automatic ROI" (thershold 50\%) for all images.

Radiation treatment. Cells and mice were irradiated with a single dose of 2 Gy using an $x-$ ray biological irradiator operating at $12 \mathrm{~mA} / 190 \mathrm{kv}$ (RADGIL, Gilardoni, Lecco, Italy). Cells were irradiated at a dose rate of $0,65 \mathrm{~Gy} / \mathrm{min}$. Mice were irradiated at a dose rate of $0,4 \mathrm{~Gy} / \mathrm{min}$ in an inhouse designed lead irradiation jig that allowed only the head to be exposed and shielded the body. 
In vitro nanovector intracellular uptake. U87MG , A172, T98G were seeded on glass cover slips (16 mm diameter) at a density of 15.000 cells/coverslip in the presence of $5 \%$ FCS. After $24 \mathrm{~h}$ of culture, the cells were incubated with targeted (Ag-PNP-CTX) or non-targeted (AgPNP) nanovectors at Ag concentration of $100 \mu \mathrm{M}$ for 16-18 hours (overnight). One hour before cell fixation, Syto Blue $45 \circledR$ fluorescent dye (Life Technologies Corporation, Carlsbad, Ca, USA) was added to the medium (1:1000). After three washes in Dulbecco's Phosphate Buffered Saline (PBS) (Sigma-Aldrich, St. Louis,MO, USA), cells were fixed in 4\% paraformaldehyde for $15 \mathrm{~min}$ at room temperature. Glasses were mounted with a PBS/Glicerol (Sigma-Aldrich, St. Louis, MO, USA), mixture (1:1) added with DAPI (Sigma-Aldrich, St. Louis, MO, USA), fluorescent stain 1:40.000.

Immunostaining. Before immunostaining fixed 10-micron-thick frozen brain section were heat antigen retrieved in Sodium Citrate $(\mathrm{pH}=6)$. Unspecific binding was blocked with $10 \%$ horse serum (Sigma) diluted in PBS/Triton 0,1\% (1 hour). Primary antibodies against human-nestin clone 2C1.3A11 (1:250 1h RT) (Abcam), human-MMP-2 (1:100 1h RT) (Sigma/Prestige Antibodies), human-CICN3 (1:100 1h RT) (Cell Signaling Technology, Beverly, MA,USA), human-LAMP1 (BD Bioscience) (1:100 1h RT) and mouse-claudin-5 (1:600 24h $\left.4^{\circ} \mathrm{C}\right)$ (Millipore) were employed at same experimental conditions for both cell lines and brain cryosections. After primary antibody, samples were incubated with the appropriate secondary antibodies conjugated with one of the indicated fluorophores, Alexa fluor: 488,555, 561 (Invitrogen) (dilution 1:200; 1 hour RT). Early endosome were marked using CellLight Early Endosome-RFP, BacMan 2.0 (Invitrogen) according to the procedure instruction.

TUNEL assay. Detection of apoptosis was carried out by in situ TUNEL-assay (Click-iTß TUNEL Alexa Fluor® 633 Invitrogen-Life Technologies, Grand Island, NY, USA). TUNEL was performed according to the protocol provided by the manufacturer. Briefly, after slide incubation (10 minutes at $37^{\circ} \mathrm{C}$ ) in $\mathrm{TdT}$ reaction buffer, samples were incubated with TdT reaction mixture for 60 minutes at $37^{\circ} \mathrm{C}$. After washes with PBS1x sections were washed with $3 \%$ BSA and $0.1 \%$ Triton ${ }^{\circledR} \mathrm{X}-100$ in PBS for 5 minutes. The Click-iT® Plus TUNEL reaction cocktail was added to each slide for 30 minutes at $37^{\circ} \mathrm{C}$.

Confocal microscopy and images analysis. Confocal microscopy was performed using a Leica TCS SP5 confocal microscope equipped with a resonant scanner (scan speed $8000 \mathrm{~Hz}$ ) and a HCX PL APO 63x/1.4 OIL objective, a HC PL FLUOTAR 10.0x0.30 DRY and a HC PL FLUOTAR 20.0x0.50 DRY. Ag-nanoparticles (nps) were acquired in reflection mode upon $458 \mathrm{~nm}$ excitation for in vitro cell experiments and upon 488nm excitation for in vivo experiments on brain cryosections. Syto blue was excited by the $458 \mathrm{~nm}$ laser line, nestin and phalloidin by the $488 \mathrm{~nm}$ 
line of an Argon laser, claudin, MMP-2 and CIC-3 by the $561 \mathrm{~nm}$ laser line of a diode laser. Voxel size was established using Nyquist criteria.

Intracellular Ag-nps quantification was carried out by 3D imaging analysis by means of IMARIS software (Bitplane, IMARIS) using the "Cells" function and the following set-up: cell detection/smooth filter $=0,160$; Background Subtraction, sphere diameter=20; Detect Vesicles, Estimated Diameter= $240 \mathrm{~nm}$; Vesicle Quality=18).

Ag uptake analysis in vivo was performed using IMARIS software using the "Spots" function into a fixed area $\left(6500 \mu \mathrm{m}^{2}\right)$ for all fields, murine or human xenograft sites.

MMP-2 and CLC-3 levels expression analysis was performed using Image $\mathrm{J}$ software. In brief, the central, the upper and the lower section of a $6 \mu \mathrm{m}$ z-stack was analyzed for each image. MMP-2 and CIC-3 Threshold mask was kept constant and using the tool "Analyze Particles" area of MMP-2 and CIC-3 signal was calculated. MMP-2 and CIC-3 area was normalized on number of nuclei present in the slice analyzed.

Western Blotting . Approximately $2 \times 10^{5}$ U87MG cells were lysed in ice-cold lysis buffer (100 mM Hepes, 2mM EDTA, 1\% SDS) supplemented with protease inhibitors (ROCHE) and then stored at $-80^{\circ} \mathrm{C}$ until used. Protein concentrations were determined using a BCA protein assay (Pierce). Equal amounts of protein $(20 \mu \mathrm{g})$ were loaded on $10 \%$ polyacrylamide gels and resolved on SDS-PAGE. Membranes were blocked ( 1 hour RT) with $5 \%$ milk in PBS/tween-20 0,1\% (Sigma) and then probed (1 hour RT) with anti-human MMP-2 polyclonal rabbit antibody (1:1000) (Sigma), anti-human CIC-3 monoclonal rabbit antibody (1:1000) (Cell Signaling Technology, Beverly, MA,USA) and anti-human $\beta$-actin monoclonal mouse antibody (1:5000) (Sigma). Antirabbit and anti-mouse HRP-conjugated secondary antibodies (Pierce, Rockford, IL, USA) were employed at a dilution of 1:5000 for 1 RT. Bands were visualized by Bio-Rad Clarity western ECL substrate (Biorad, Hercules, USA), and detected by ChemiDoc MP system (Biorad, Hercules, USA). All densitometric analyses were carried out using Image Lab software version 5.1 (Biorad Hercules, USA).

Gelatin Zymography. Supernatant from in vitro grown U87MG cells were eluted in Zymogram Sample Buffer (Biorad, Hercules, USA) according to producer instructions. Equal amount of each samples were loaded in Ready Gel® Zymogram Precast Gels (Biorad, Hercules, USA) and electrophoresis was carried out at fixed voltage of $90 \mathrm{~V}$. The gels were washed twice in distilled water for 10' and twice in Zymogram Renaturation Buffer (Biorad, Hercules, USA) for $30^{\prime}$ and then incubated for 6 hours at $37^{\circ} \mathrm{C}$ in Zymogram Development Buffer (Biorad, Hercules, USA). After incubation, gels were stained with Bio-Safe Coomassie Stain (Biorad, Hercules, USA) for 2 hours. Gelatinolytic activity was detected as transparent bands on a blue background. Images 
were acquired with chemidoc system (Biorad, Hercules, USA). Densitometry analysis was performed with ImageJ Software.

MTT Assay. U87MG cells (5,000 cells/well) were plated in 96-well plates with $100 \mu \mathrm{l} \alpha \mathrm{MEM}$ medium. After $24 \mathrm{~h}$ cells were treated with increasing concentrations of Ag-nps encapsulated in the PNP nanovectors, whereas no treatment was done as positive proliferation control. At $72 \mathrm{~h}, 25 \mu \mathrm{l}$ of $5 \mathrm{mg} / \mathrm{ml}$ 3-(4,5-dimethylthiazol-2-yl)-2,5-diphenyltetrazolium bromide (MTT, Sigma-Aldrich, St Louis, MO) was added directly to the cells followed by an additional 4 hours of incubation, then 100 $\mu \mathrm{L}$ of DMSO was added. The optical density of individual wells was measured at a wavelength of $550 \mathrm{~nm}$ with the Sunrise apparatus (Tecan Group, Ltd, Mannedorf, Switzerland). All assays were performed in triplicate.

Statistics. Data are presented as mean \pm SE. If not indicated mean values were compared by the Student's $t$ test (two-tailed, non parametric). Statistics and fitting of experimental data were performed with Graph Pad Prism6.

\section{ACKNOWLEDGEMENT}

We thank Dr. Lorenzo Bello (Humanitas and University of Milano), Dr. Elisabetta Menna (IN-CNR) and Dr. Davide Pozzi (Fondazione Humanitas per la Ricerca) for suggestions. We acknowledge Prof. Giulio Maira and Dr. Maurizio Fornari (Humanitas Research Hospital) for critically reading the manuscript and for continuous constructive discussions. This work was supported by Fondazione "Giancarla Vollaro", Via Filodrammatici 10, Milano, by CNR InterOmics Flagship Project to M.M. (ID B92I15000140001) and by CEN Foundation, Piazza Leonardo da Vinci 32, Milano (Start-up Packages and PhD Program" project, co-funded by Regione Lombardia through the program "Fondo per lo Sviluppo e la Coesione 2007-2013", ex FAS" ).

\section{SUPPORTING INFORMATION AVAILABLE:}

Ag-NP-CTX biodistribution in peripheral organs, bright field images of cryosections of tumor tissues from U87MG orthotopic xenografts inoculated with Ag-PNPCTX nanovectors, bright field magnified images of cells reported in Figure $6 \mathrm{D}$. 


\section{REFERENCES AND NOTES}

1 Bastien, J. I.; McNeill, K. A.; Fine, H. A. Molecular characterizations of glioblastoma, targeted therapy, and clinical results to date. Cancer. 2015, 121, 502-516.

2 Villa, S.; Balana, C.; Comas, S. Radiation and concomitant chemotherapy for patients with glioblastoma multiforme. Chin J Cancer. 2014, 33, 25-31.

3 Stupp, R; Mayer, M.; Kann, R.; Weder, W.; Zouhair, A.; Betticher, D. C.; Roth, A. D.; Stahel, R. A.; Majno, S. B.; Peters, S.; et al. Neoadjuvant chemotherapy and radiotherapy followed by surgery in selected patients with stage IIIB non-small-cell lung cancer: a multicentre phase II trial. Lancet Oncol. 2009, 10, 785-793.

4 Kreuter, J. Drug delivery to the central nervous system by polymeric nanoparticles: what do we know? Adv Drug Deliv Rev. 2014, 71, 2-14.

5 Agarwal, S.; Manchanda, P.; Vogelbaum, M. A.; Ohlfest, J. R.; Elmquist, W. F. Function of the blood-brain barrier and restriction of drug delivery to invasive glioma cells: findings in an orthotopic rat xenograft model of glioma. Drug Metab Dispos. 2013, 41, 33-39.

6 Woodworth, G. F.; Dunn, G. P.; Nance, E. A.; Hanes, J.; Brem, H. Emerging insights into barriers to effective brain tumor therapeutics. Front Oncol. 2014, 4, 126, doi:10.3389/fonc.2014.00126 .

7 Wohlfart, S.; Gelperina, S.; Kreuter, J. Transport of drugs across the blood-brain barrier by nanoparticles. J Control Release. 2012, 161, 264-273.

8 Acharya, S.; Sahoo, S. K. PLGA nanoparticles containing various anticancer agents and tumour delivery by EPR effect. Adv Drug Deliv Rev. 2011, 63, 170-183.

9 Gao, Z.; Zhang, L.; Sun, Y. Nanotechnology applied to overcome tumor drug resistance. J Control Release. 2012, 162, 45-55.

10 Locatelli, E.; Gil, L.; Israel, L. L.; Passoni, L.; Naddaka, M.; Pucci, A.; Reese, T.; Gomez-Vallejo, V.; Milani, P.; Matteoli, M.; et al. Biocompatible nanocomposite for PET/MRI hybrid imaging. Int J Nanomedicine. 2012, 7, 6021-6033.

11 Danhier, F.; Ansorena, E.; Silva, J. M.; Coco, R.; Le Breton, A.; Preat, V. PLGA-based nanoparticles: an overview of biomedical applications. J Control Release. 2012, 161, 505-522.

12 Kunwar, S.; Chang, S.; Westphal, M.; Vogelbaum, M.; Sampson, J.; Barnett, G.; Shaffrey, M.; Ram, Z.; Piepmeier, J.; Prados, M.; et al. Phase III randomized trial of CED of IL13-PE38QQR vs Gliadel wafers for recurrent glioblastoma. Neuro Oncol. 2010, 12, 871-881.

13 Sawyer, A. J.; Saucier-Sawyer, J. K.; Booth, C. J.; Liu, J.; Patel, T.; Piepmeier, J. M.; Saltzman, W. M. Convection-enhanced delivery of camptothecin-loaded polymer nanoparticles for treatment of intracranial tumors. Drug Deliv Transl Res. 2011, 1, 34-42.

14 Thorne, R. G.; Nicholson, C. In vivo diffusion analysis with quantum dots and dextrans predicts the width of brain extracellular space. Proc Natl Acad Sci U.S.A. 2006, 103, 5567-5572.

15 Hobbs, S. K.; Monsky, W. L.; Yuan, F.; Roberts, W. G.; Griffith, L.; Torchilin, V. P.; Jain, R. K. Regulation of transport pathways in tumor vessels: role of tumor type and microenvironment. Proc Natl Acad Sci U.S.A. 1998, 95, 4607-4612.

16 Gao, H.; Yang, Z.; Zhang, S.; Cao, S.; Shen, S.; Pang, Z.; Jiang, X. Ligand modified nanoparticles increases cell uptake, alters endocytosis and elevates glioma distribution and internalization. Sci Rep. 2013, 3, 2534, doi:10.1038/srep02534.

17 Soroceanu, L.; Gillespie, Y.; Khazaeli, M. B.; Sontheimer, H. Use of chlorotoxin for targeting of primary brain tumors. Cancer Res. 1998, 58, 4871-4879.

18 DeBin, J. A.; Maggio, J. E.; Strichartz, G. R. Purification and characterization of chlorotoxin, a chloride channel ligand from the venom of the scorpion. Am J Physiol. 1993, 264, C361-369.

19 Deshane, J.; Garner, C. C.; Sontheimer, H. Chlorotoxin inhibits glioma cell invasion via matrix metalloproteinase-2.J Biol Chem. 2003, 278, 4135-4144.

20 Lui, V. C.; Lung, S. S.; Pu, J. K.; Hung, K. N.; Leung, G. K. Invasion of human glioma cells is regulated by multiple chloride channels including CIC-3. Anticancer Res. 2010, 30, 4515-4524.

21 McFerrin, M. B.; Sontheimer, H. A role for ion channels in glioma cell invasion. Neuron Glia Biol. 2006, 2, 39-49. 
22 Yuan, H.; Gaber, M. W.; McColgan, T.; Naimark, M. D.; Kiani, M. F.; Merchant, T. E. Radiation-induced permeability and leukocyte adhesion in the rat blood-brain barrier: modulation with anti-ICAM-1 antibodies. Brain Res. 2003, 969, 59-69.

23 d'Avella, D.; Cicciarello, R.; Albiero, F.; Mesiti, M.; Gagliardi, M. E.; Russi, E.; d'Aquino, A.; Tomasello, F.; d'Aquino, S. Quantitative study of blood-brain barrier permeability changes after experimental wholebrain radiation. Neurosurgery. 1992, 30, 30-34.

24 Kwak, S. Y.; Kim, B. Y.; Ahn, H. J.; Yoo, J. O.; Kim, J.; Bae, I. H.; Han, Y. H. et al. Ionizing radiation-inducible miR-30e promotes glioma cell invasion through EGFR stabilization by directly targeting CBL-B. FEBS J. 2015 doi:10.1111/febs.13238.

25 Park, C. M.; Park, M. J.; Kwak, H. J.; Lee, H. C.; Kim, M. S.; Lee, S. H.; Park, I. C.; Rhee, C. H.; Hong, S. I. Ionizing radiation enhances matrix metalloproteinase-2 secretion and invasion of glioma cells through Src/epidermal growth factor receptor-mediated p38/Akt and phosphatidylinositol 3-kinase/Akt signaling pathways. Cancer Res. 2006, 66, 8511-8519.

26 Lee, W. H.; Warrington, J. P.; Sonntag, W. E.; Lee, Y. W. Irradiation alters MMP-2/TIMP-2 system and collagen type IV degradation in brain. Int J Radiat Oncol Biol Phys. 2012, 82, 1559-1566.

27 Badiga, A. V.; Chetty, C.; Kesanakurti, D.; Are, D.; Gujrati, M.; Klopfenstein, J. D.; Dinh, D. H.; Rao, J. S. MMP-2 siRNA inhibits radiation-enhanced invasiveness in glioma cells. PLoS One. 2011, 6, e20614, doi:10.1371/journal.pone.002061410-PONE-RA-19742.

28 Ulasov, I.; Thaci, B.; Sarvaiya, P.; Yi, R.; Guo, D.; Auffinger, B.; Pytel, P.; Zhang, L.; Kim, C. K.; Borovjagin, A.; et al. Inhibition of MMP14 potentiates the therapeutic effect of temozolomide and radiation in gliomas. Cancer Med. 2013, 2, 457-467.

29 Locatelli, E.; Broggi, F.; Ponti, J.; Marmorato, P.; Franchini, F.; Lena, S.; Franchini, M. C. Lipophilic silver nanoparticles and their polymeric entrapment into targeted-PEG-based micelles for the treatment of glioblastoma. Adv Healthc Mater. 2012, 1, 342-347.

30 Gentili, D., Ori, G. \& Franchini, MC. Double phase transfer of gold nanorods for surface functionalization and entrapment into PEG-based nanocarriers. Chem Commun (Camb) 2009, 39, 5874-5876.

31 Locatelli, E.; Naddaka, M.; Uboldi, C.; Loudos, G.; Fragogeorgi, E.; Molinari, V.; Pucci, A.; Tsotakos, T.; Psimadas, D.; Ponti, J.; et al. Targeted delivery of silver nanoparticles and alisertib: in vitro and in vivo synergistic effect against glioblastoma. Nanomedicine (Lond). 2014, 9, 839-849.

32 Saluja, S. S.; Hanlon, D. J.; Sharp, F. A.; Hong, E.; Khalil, D.; Robinson, E.; Tigelaar, R.; Fahmy, T. M.; Edelson, R. L. Targeting human dendritic cells via DEC-205 using PLGA nanoparticles leads to enhanced cross-presentation of a melanoma-associated antigen. Int J Nanomedicine. 2014, 9, 5231-5246.

33 Shen, H.; Ackerman, A. L.; Cody, V.; Giodini, A.; Hinson, E. R.; Cresswell, P.; Edelson, R. L.; Saltzman, W. M.; Hanlon, D. J. Enhanced and prolonged cross-presentation following endosomal escape of exogenous antigens encapsulated in biodegradable nanoparticles. Immunology. 2006, 117, 78-88.

34 Panyam, J.; Zhou, W. Z.; Prabha, S.; Sahoo, S. K.; Labhasetwar, V. Rapid endo-lysosomal escape of poly(DL-lactide-co-glycolide) nanoparticles: implications for drug and gene delivery. FASEB J. 2002,16, 1217-1226.

35 Miconi, G.; Palumbo, P.; Raysi Dehcordi, S.; La Torre, C.; Lombardi, F.; Evtoski, Z.; Cimini, A. M.; Galzio, R.; Cifone, M. G.; Cinque, B. Immunophenotypic characterization of human glioblastoma stem cells: correlation with clinical outcome. J Cell Biochem. 2015, 116, 864-876.

$36 \mathrm{Jia}$, W.; Lu, R.; Martin, T. A.; Jiang, W. G. The role of claudin-5 in blood-brain barrier (BBB) and brain metastases (review). Mol Med Rep. 2014, 9, 779-785.

37 Hardee, M. E.; Zagzag, D. Mechanisms of glioma-associated neovascularization. Am J Pathol. 2012, 181, 1126-1141.

38 Engelhardt, S.; Patkar, S.; Ogunshola, O. O. Cell-specific blood-brain barrier regulation in health and disease: a focus on hypoxia. Br J Pharmacol. 2014, 171, 1210-1230.

39 Ernsting, M. J.; Murakami, M.; Roy, A.; Li, S. D. Factors controlling the pharmacokinetics, biodistribution and intratumoral penetration of nanoparticles. J Control Release. 2013, 172, 782-794.

40 Jordan, C. T.; Guzman, M. L.; Noble, M. Cancer stem cells. N Engl J Med. 2006, 355, 1253-1261.

41 Mannino, M.; Chalmers, A. J. Radioresistance of glioma stem cells: intrinsic characteristic or property of the 'microenvironment-stem cell unit'? Mol Oncol. 2011, 5, 374-386. 
43 Bjorklund, M.; Koivunen, E. Gelatinase-mediated migration and invasion of cancer cells. Biochim Biophys Acta. 2005, 1755, 37-69.

43 Urbanska, K. ; Pajak, B.; Orzechowski, A; .Sokolowska, J.; Grodzik, M.; Sawosz, E.; Szmidt, M.; Sysa, P. The effect of silver nanoparticles (AgNPs) on proliferation and apoptosis of in ovo cultured glioblastoma multiforme (GBM) cells. Nanoscale Res Lett. 2015, 10, 98.

\section{ToC Graphic}

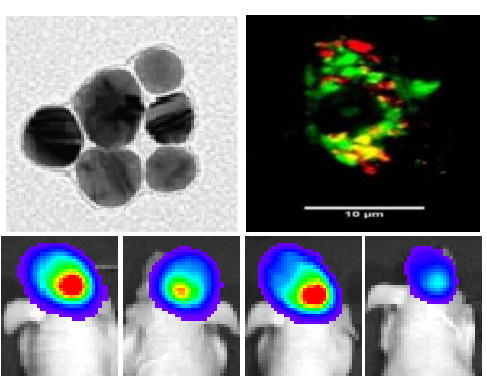


25 Figure 1. (A) Schematic procedure for the synthesis of Ag-PNP-CTX. Representative TEM image 26 (B) DLS analysis (C) and ל-potential analysis (D) of Ag-PNP-CTX.

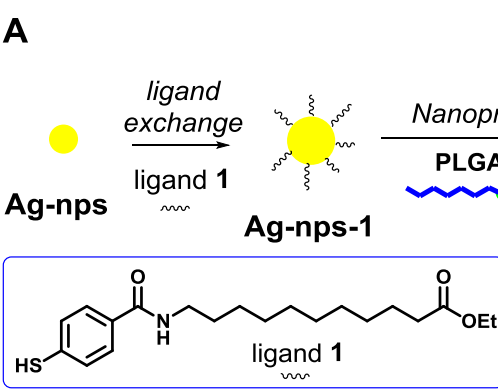

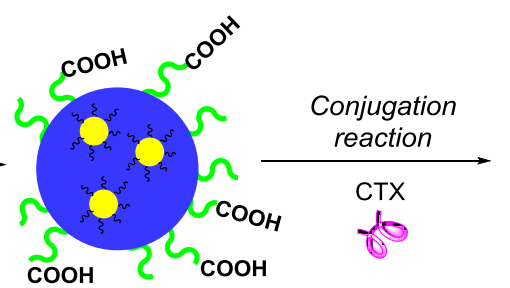

Ag-PNP

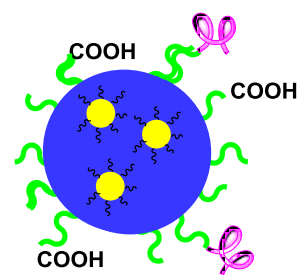

Ag-PNP-CTX

$\boldsymbol{d}=114 \pm 2 \mathrm{~nm} \quad \zeta$-pot $=-31.6 \mathrm{mV}$ $P D I=0.21 \pm 0.01 \mathrm{Ag}=3.81 \mathrm{mM}$

B

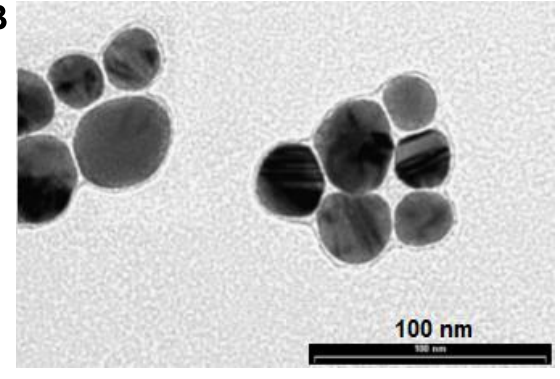

C

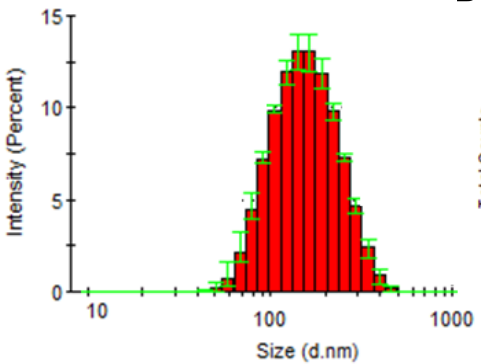

D

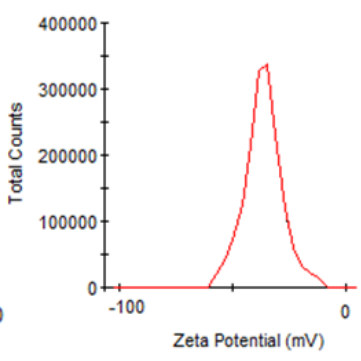



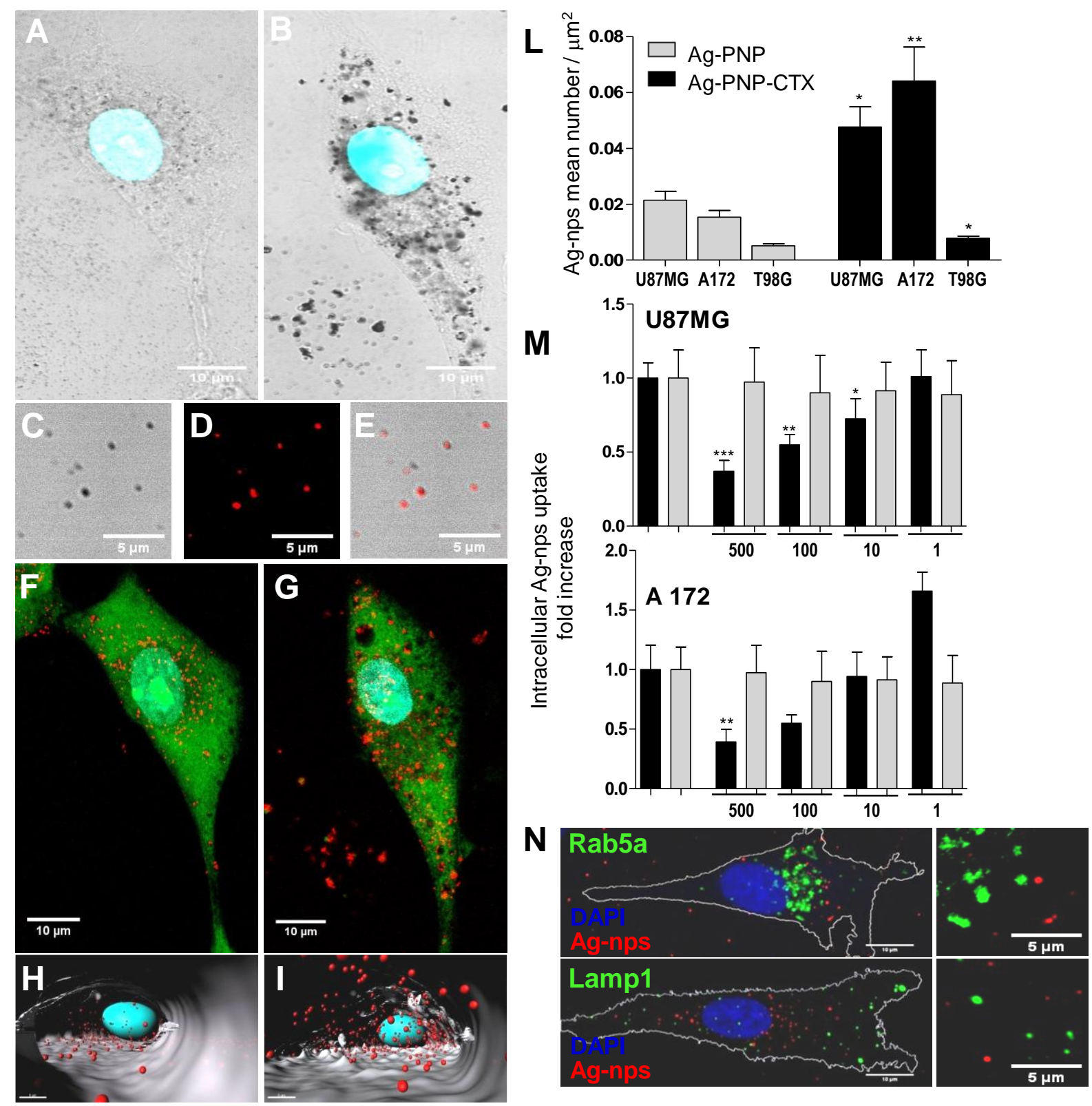
Figure 2. Human-derived GBM cell lines U87MG, $A 172$ and T98G were incubated $\mathrm{o} / \mathrm{n}$ in the presence of targeted (Ag-PNP-CTX) or non-targeted (Ag-PNP) nanovectors at Ag concentration of $100 \mu \mathrm{M}$. The intracellular accumulation of $\mathrm{Ag}$ nanoparticles (Ag-nps) was determined by confocal laser scanning microscopy $(A, B, F, G)$ and $3 D$ imaging analysis performed by IMARIS software (H and $I)$. (A) and (B) bright field images. (C-E) Pictures of Ag-nps: (C) bright field, (D) reflection mode (as for figures $F$ and $G$ ), $(E)$ merge. $(F)$ and $(G)$ images represent the maximum projections of 20 optical sections of the cell labelled with Syto Blue $45 \AA$ (green). Metal Ag-nps have been acquired in reflection mode upon $458 \mathrm{~nm}$ excitation and are shown in red and DAPI signal for nuclei detection in blue. $(\mathrm{H})$ and $(\mathrm{I})$ computation $3 \mathrm{D}$ images of the peri-nuclear region of cells in panel $\mathrm{F}$ and $\mathrm{G}$ respectively. (L) Intracellular Ag-nps quantification expressed as mean number of Ag-nps ES normalized on the cell surface $\left(\mu \mathrm{m}^{2}\right)$. About 60 cells / experimental group from 2 or 3 independent experiments were analyzed. Significance versus cells incubated with non-targeted nanovector (AgPNP): * $p<0,02 ;{ }^{* *} p<0,005$. (M) Competitive inhibition of cellular uptake of Ag-PNP-CTX and Ag-PNP nanovectors in U87MG and A172 cells incubated with native CTX peptide at the indicated concentrations ( $\mathrm{ng} / \mathrm{ml})$. Results are expressed as Ag-nps quantity ES normalized to the Ag-nps detected in cells incubated without native CTX peptide (first columns). Significance versus cells incubated in the absence of CTX peptide: U87MG * $p=0,0334^{* *} p=0,0057{ }^{* * *} p=0,0004$; A 172 ** $p=0,0052$. (N) Representative confocal microscopy images showing U87-MG cells incubated in the presence of Ag-PNP-CTX nanovectors. Intracellular endosomal and lysosomal compartments were identified using the specific-associated markers Rab5a and LAMP-1 respectively. 

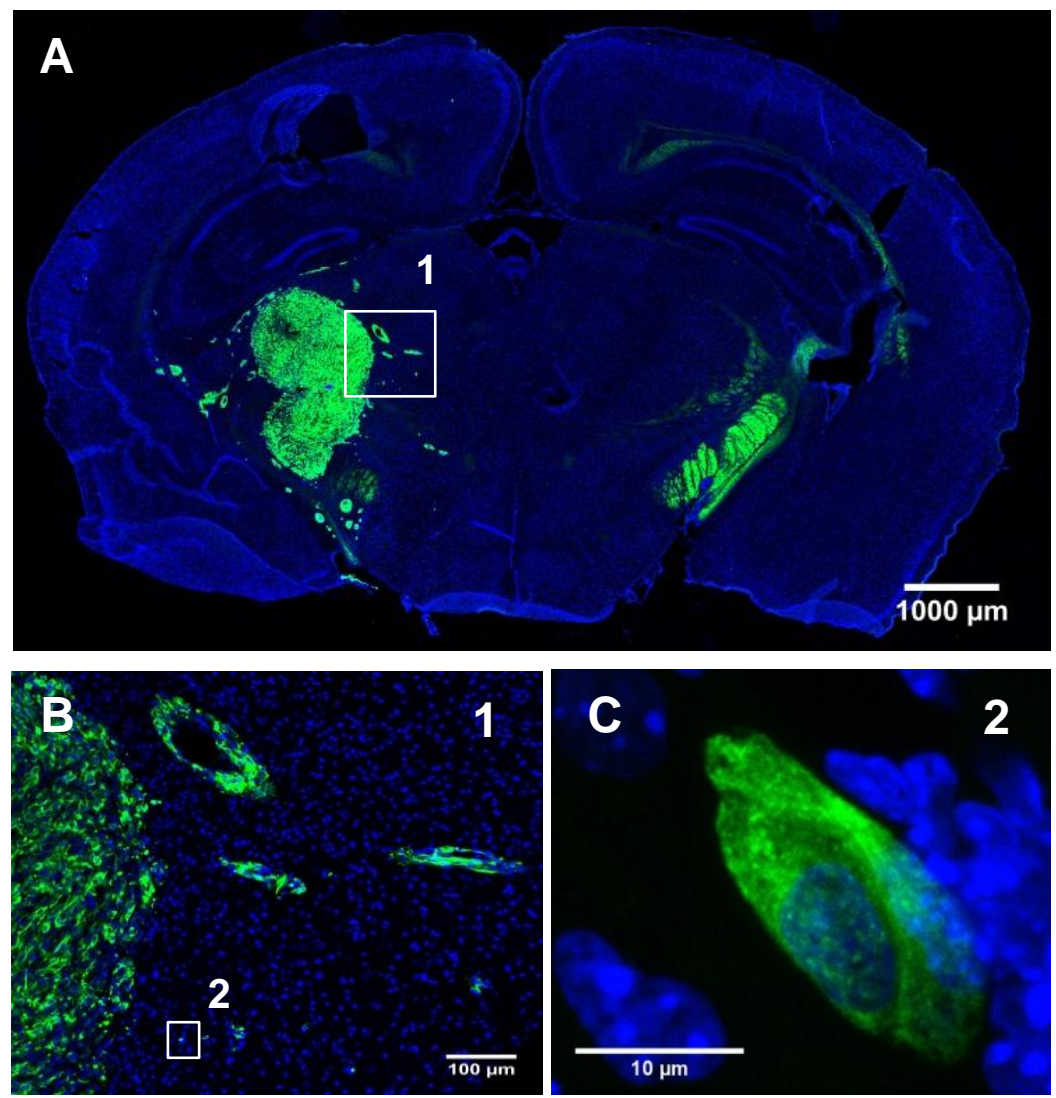

Figure 3. U87MG $\left(5 \times 10^{4}\right)$ cells were injected intracerebrally into athymic 6-8 weeks old male mice. After 2 weeks, animals were euthanized with intracardiac perfusion of PBS, followed by formaldehyde. GBM xenografts were detected by immune staining for human nestin (green). In blue is the DAPI signal for nuclei detection. (A) representative coronal section 15 days after tumor implantation; $(B)$ and $(C)$ magnified views of the indicated insets. 


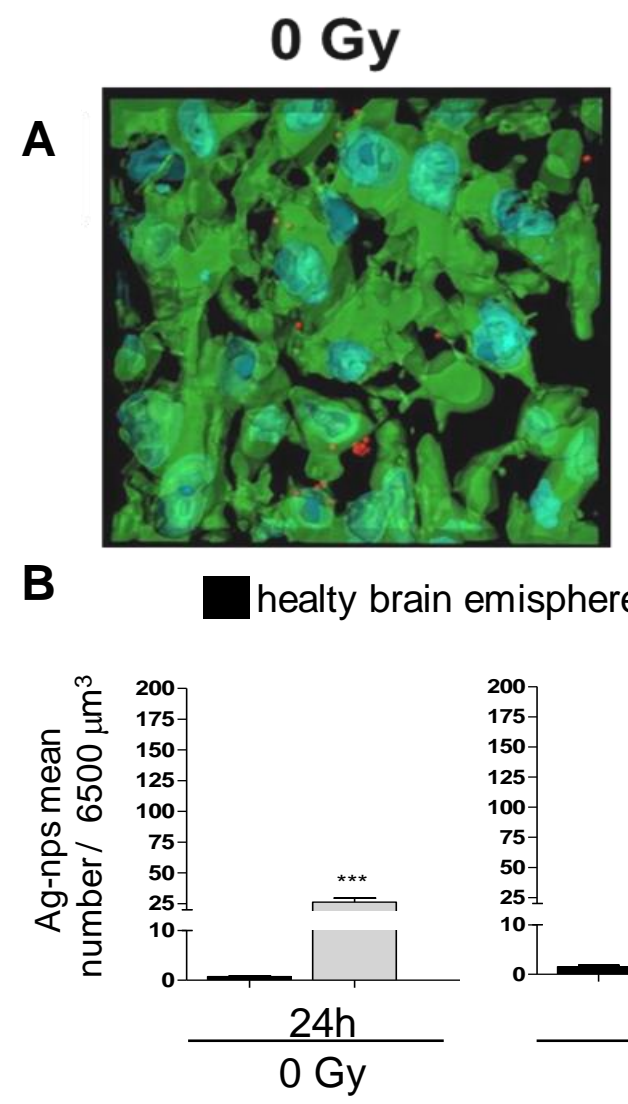

\section{Gy}

B

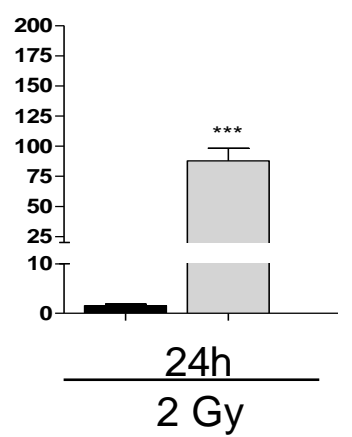

2 Gy

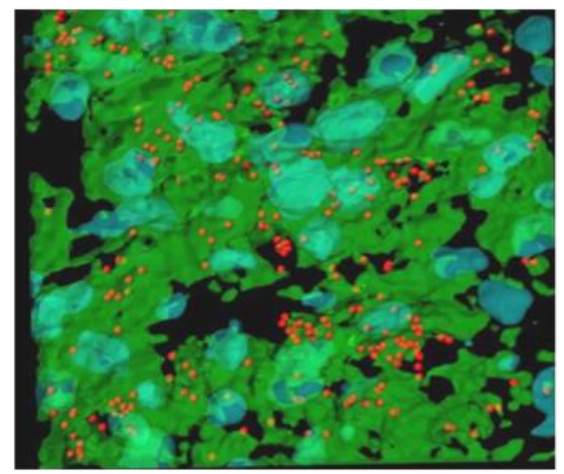

U87MG tumor

31 Figure 4 In vivo accumulation of Ag-PNP-CTX nanovectors at tumor site assessed in U87MG 32 orthotopic xenografts model. Fifteen days after implantation of tumor cells mice were subjected to 34 total brain radiation treatment (2Gy). A parallel group of non-irradiated mice (0 Gy) was considered 35 as control. Ag-PNP-CTX were administered intraperitoneally 18 hours after radiations at a dose of $361 \mathrm{mg} / \mathrm{mouse}$. Animals were sacrificed 24 or 48 hours after nanovector injection. Ag-nps quantification 37 was performed in brain cryosections by confocal microscopy and IMARIS 3D imaging analysis as in 38Supplementary Figure 1. (A) Cryosections of U87MG tumor mass from irradiated (2 Gy) and non39 irradiated (0 Gy) mice injected with Ag-PNP-CTX (0Gy). Ag-nps have been acquired in reflection 40 mode upon $488 \mathrm{~nm}$ excitation and are shown in red. In green is the human nestin immunostaining 41 and the nuclei are in blue (DAPI). (B) Ag-nps quantification is expressed as mean number of Ag-nps 43 ES in a fixed volume of $6500 \mu \mathrm{m}^{3}$. About 60 microscopy fields randomly taken from 4 mice in each 44 experimental group were acquired and analyzed. Significance versus healthy brain tissue: $45^{\star * *} p<0,0001$

46 

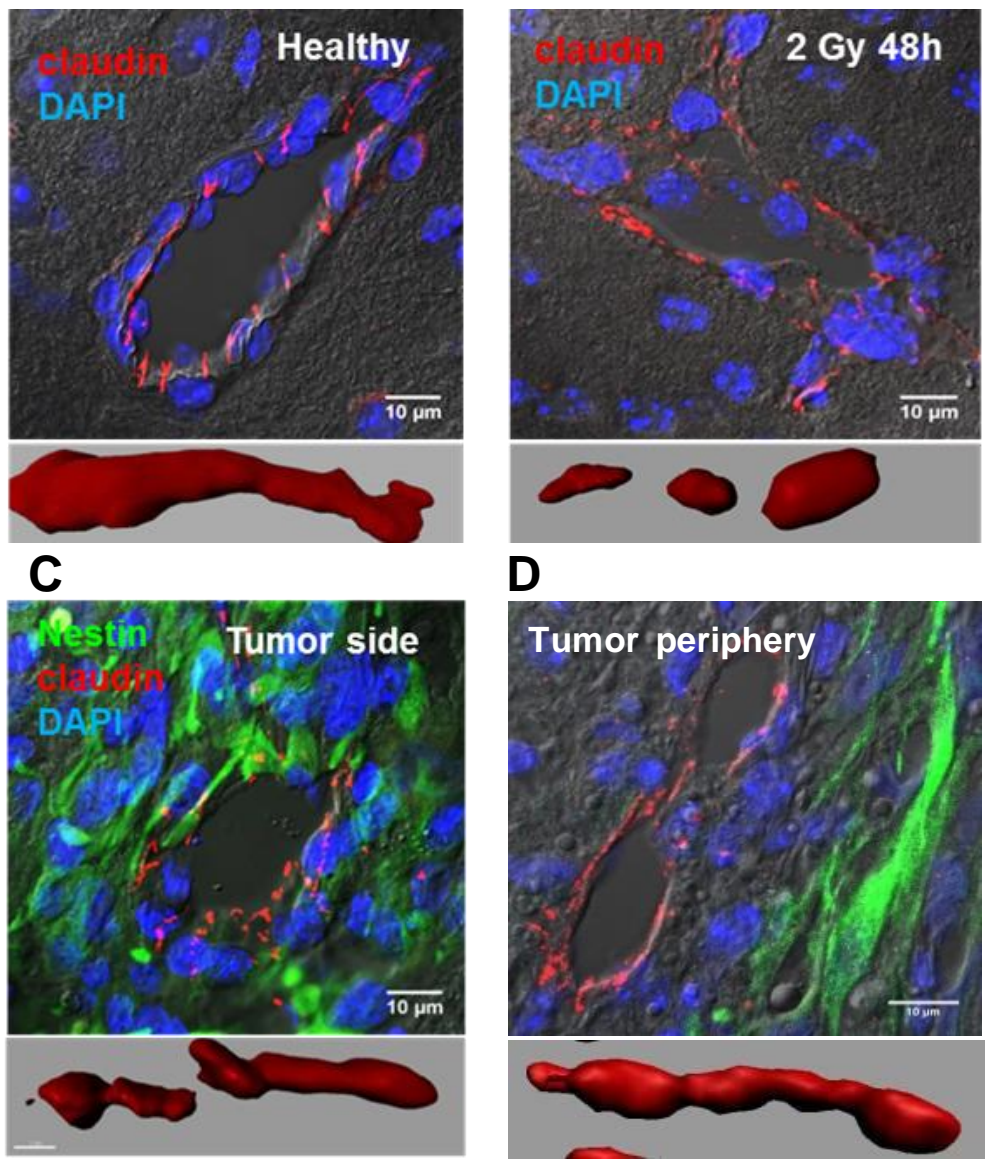

D

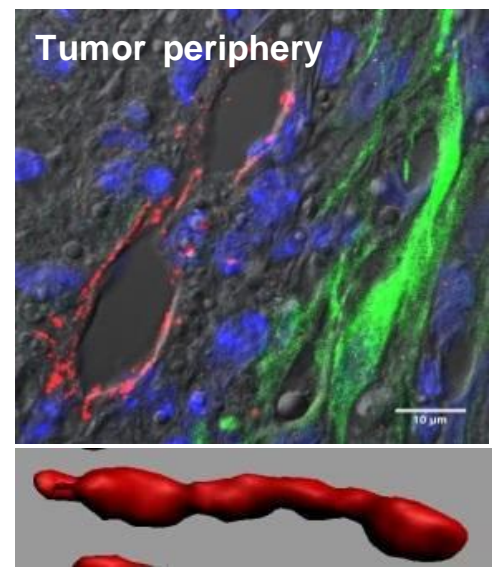

E
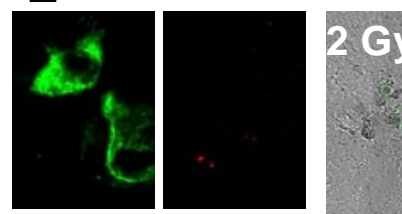

\section{Gy}

45 Figure 5. . In vivo BBB integrity and Ag-PNP-CTX nanovector diffusion in peripheral tumor areas. (A46 D) Confocal images (maximum projections) of normal and tumor-associated blood vessels. Brain 47 cryosections from U87MG-trasplanted mice previously irradiated (2Gy) or non-irradiated (0 Gy) were 48 immunostained for claudin-5 (red) and human nestin (green). Nuclei were revealed by DAPI staining 49 (blue). Lower panels are representative 3D rendering of selected regions of claudin-5 staining carried 51 out by IMARIS software. (E) Ag-nps and nestin co-localization in single cells present at the U87MG 52 tumor periphery from non-irradiated (0Gy, left panel) and irradiated (2Gy, middle and right panel) 53 mice injected with Ag-PNP-CTX. The isolated cell, labeled with antibodies recognizing human nestin 54 (in green), is a tumor cell which infiltrates the healthy mice tissue, which is negative for the human 55 nestin antibody. Ag-nps have beencesquiroboinpleffectiapompde upon $488 \mathrm{~nm}$ excitation and are 56 shown in red. In green is the human nestin immunostaining. In the bright field Ag-nps are visible as 57 black dots (middle panel). 
45 normalized on corresponding $\beta$-actin. (D) Ag-nps (red) and MMP-2 or ClC-3 (green) signals in 46 irradiated (2Gy) and non-irradiated (0 Gy) U87MG cells shown as maximum projections of 6 optical 47 sections. In blue is the nuclear staining (DAPI). Cell borders were defined by phalloidin staining 48 (gray).
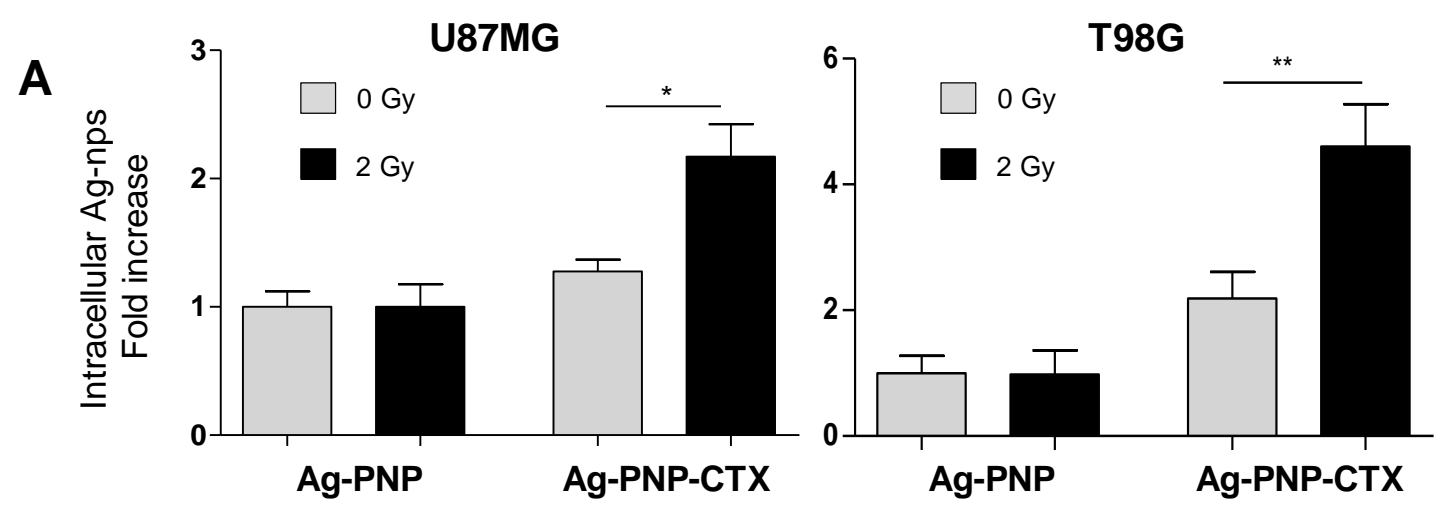

B
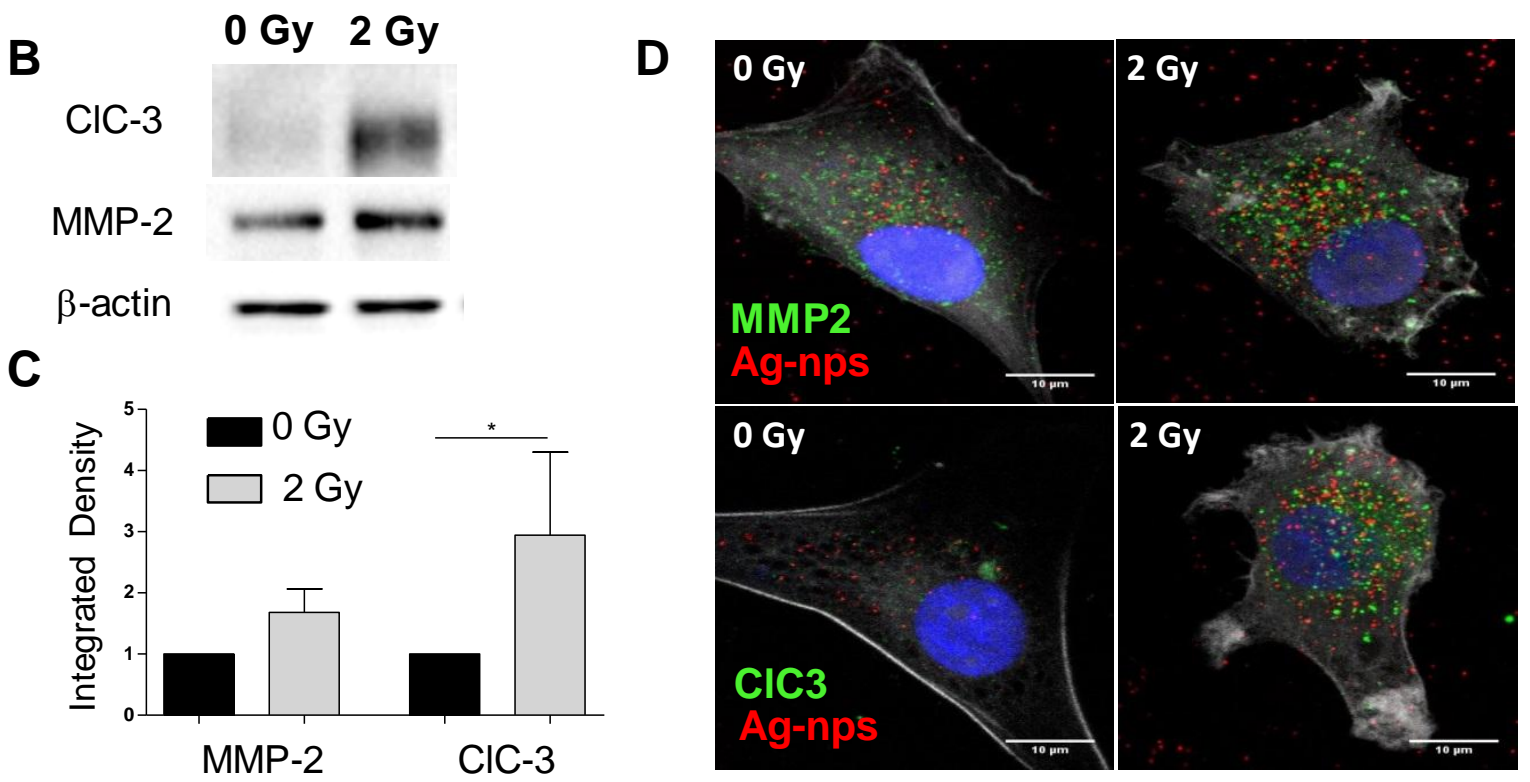

Figure 6 Radiation induced CTX-nanovector intracellular uptake, MMP-2 and CIC-3 expression. (A) Intracellular Ag-nps quantification in irradiated (2 Gy) and non-irradiated (0 Gy) U87MG or TG98 cells incubated overnight in the presence of Ag-PNP or Ag-PNP-CTX. Results are expressed as Ag-nps quantity ES normalized to the Ag-nps detected in non-irradiated cells incubated with Ag-PNP(0 Gy Ag-PNP, first column). For analysis details see also Supplementary figure 1. Significance versus non-irradiated cells: * $p=0,0117$. (B) Western-blot analysis of MMP-2 and $\mathrm{CIC}-3$ expression in irradiated and non-irradiated U87MG cells. One representative experiment out of 4 performed is reported. Levels of $\beta$-actin are reported as control for protein loading. (C) 44 Densitometry analysis of western-blot bands (panel B) performed by Image-Lab software. Results 
A MMP2

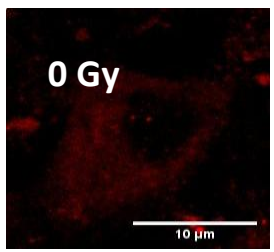

$2 \mathrm{~Gy}$
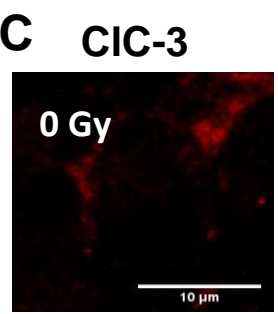

\section{Gy}

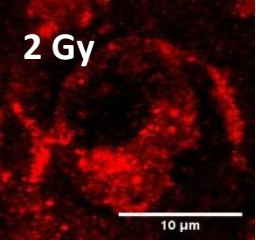

NESTIN
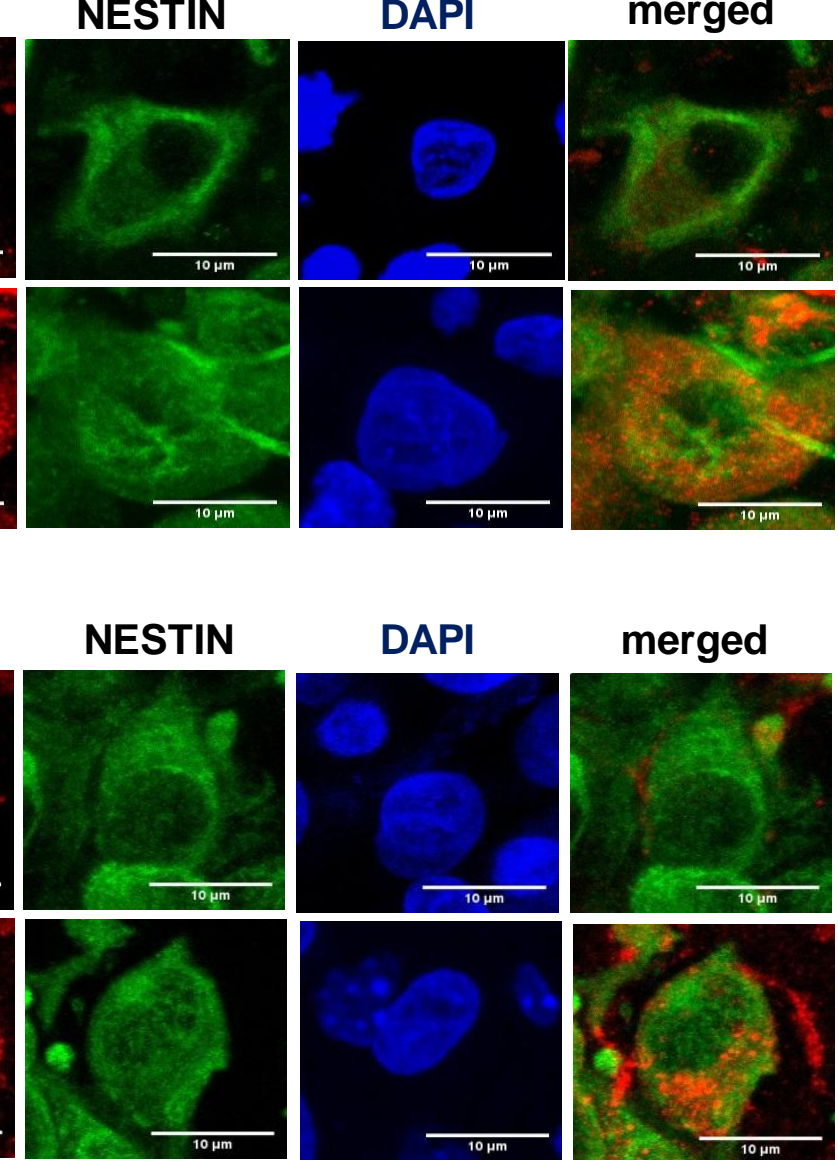

DAPI
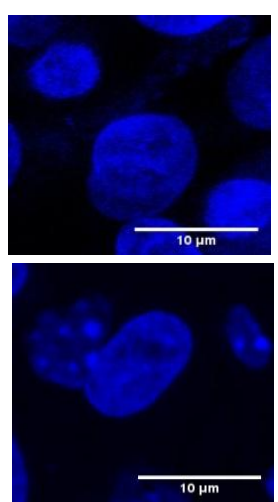

merged
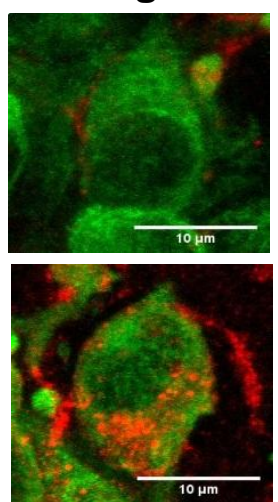

B

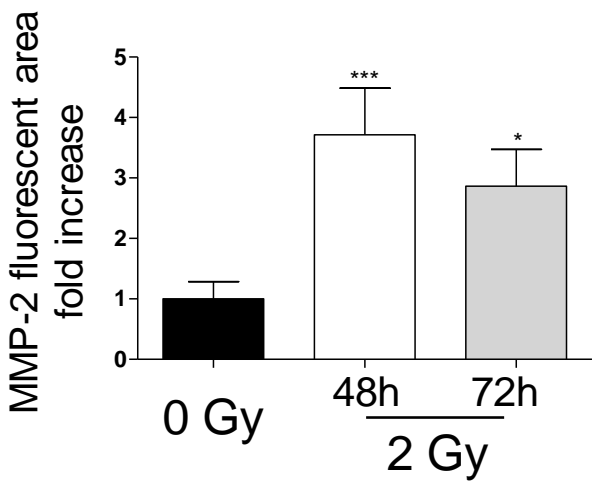

D

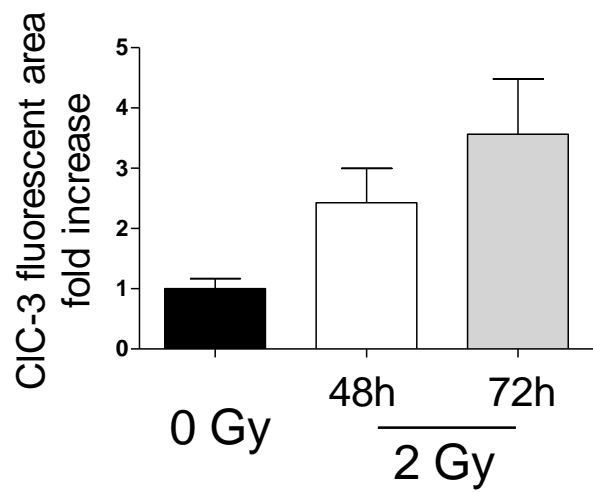

33

34 Figure 7. In vivo MMP-2 and CIC3- expression in U87MG xenograft before and after radiations. (A$35 \mathrm{C}$ ) Representative confocal images of brain cryosections from U87MG-trasplanted mice previously 37 irradiated (2Gy) or non-irradiated (0 Gy) and immunostained for human MMP-2 or CIC-3 (red) and 38 nestin (green). Nuclei were revealed by DAPI staining (blue). (B-D) In vivo MMP-2 and ClC-3 level of 39 expression quantification in U87MG xenographs 48 and 72 hours after x-rays treatment. Results are 40 expressed as increased mean MMP-2 and/or CIC-3 fluorescent area respect to non-irradiated 41 samples (0 Gy) ES. About 15 microscopy fields for each experimental condition were randomly 42 acquired and analyzed by ImageJ software. For each single microscopy field analyzed MMP-2 and/or $43 \mathrm{CIC}-3$ fluorescent area was normalized on nuclei number. MMP-2 significance versus non-irradiated 45 tumor cells * $p=0,0119 ;{ }^{* *} p=0,0005$.

46

47

48

49

50

51

52

53 

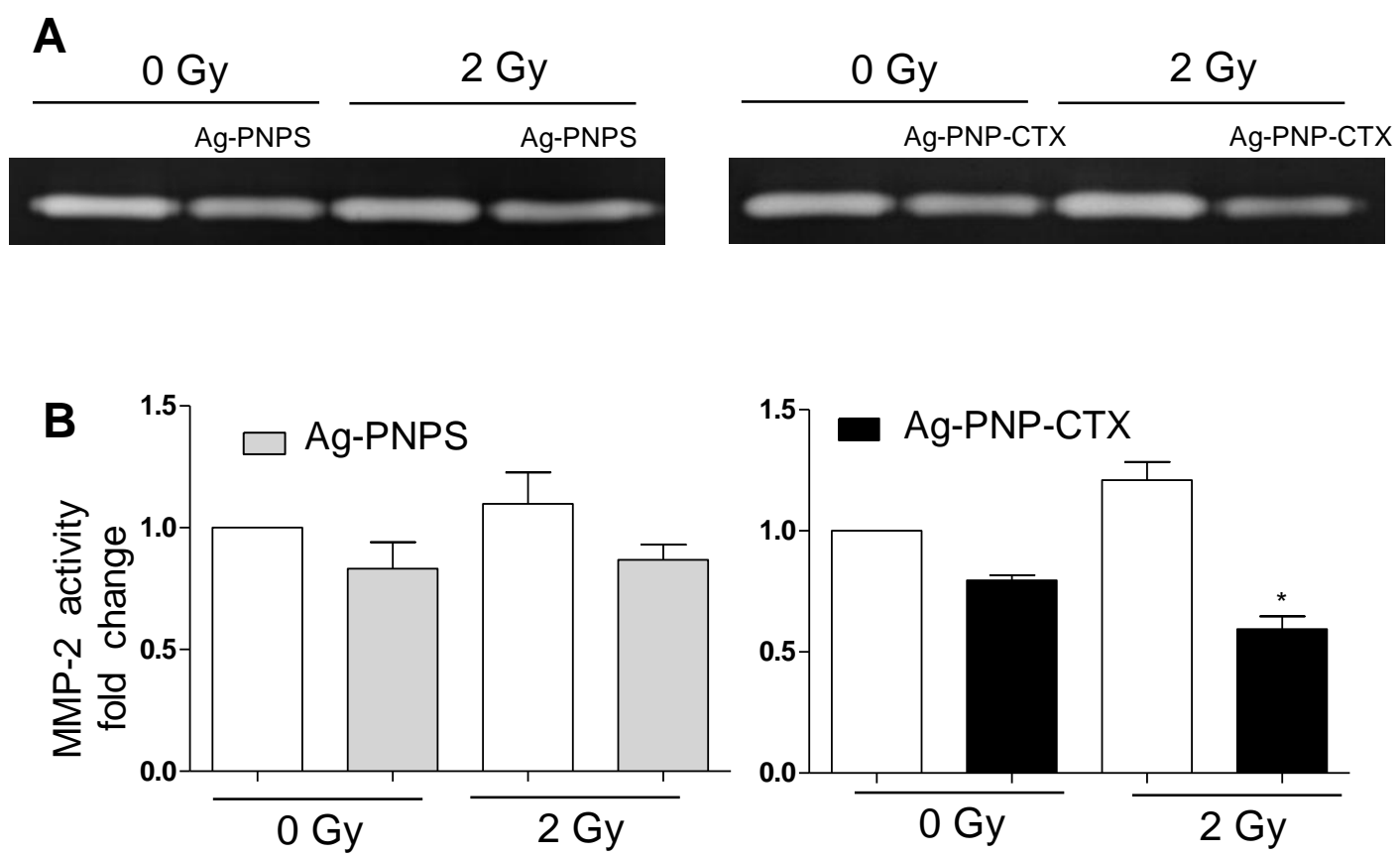

${ }^{24}$ Figure 8. Inhibition of MMP-2 catalytic activity in U87MG cells induced by Ag-PNP-CTX nanovectors. ${ }_{26}^{25}$ U87MG cells previously irradiated (2Gy) were incubated in the presence of Ag-PNP or Ag-PNP-CTX 27 nanovectors (100 uM for 16 hours). Inhibition of MMP-2 catalytic activity was evaluated by 28 zymography. (A) Representative zymography of one out of 2 independent experiments performed. 29(B) Densitometry analysis of zimography bands. Results are expressed as mean values from 2 30 independent experiments normalized to non-irradiated cells (0 Gy) ES. Statistical significance was 31 evaluated by One-way ANOVA. Significance versus irradiated cells: ${ }^{*} p<0,05$ 

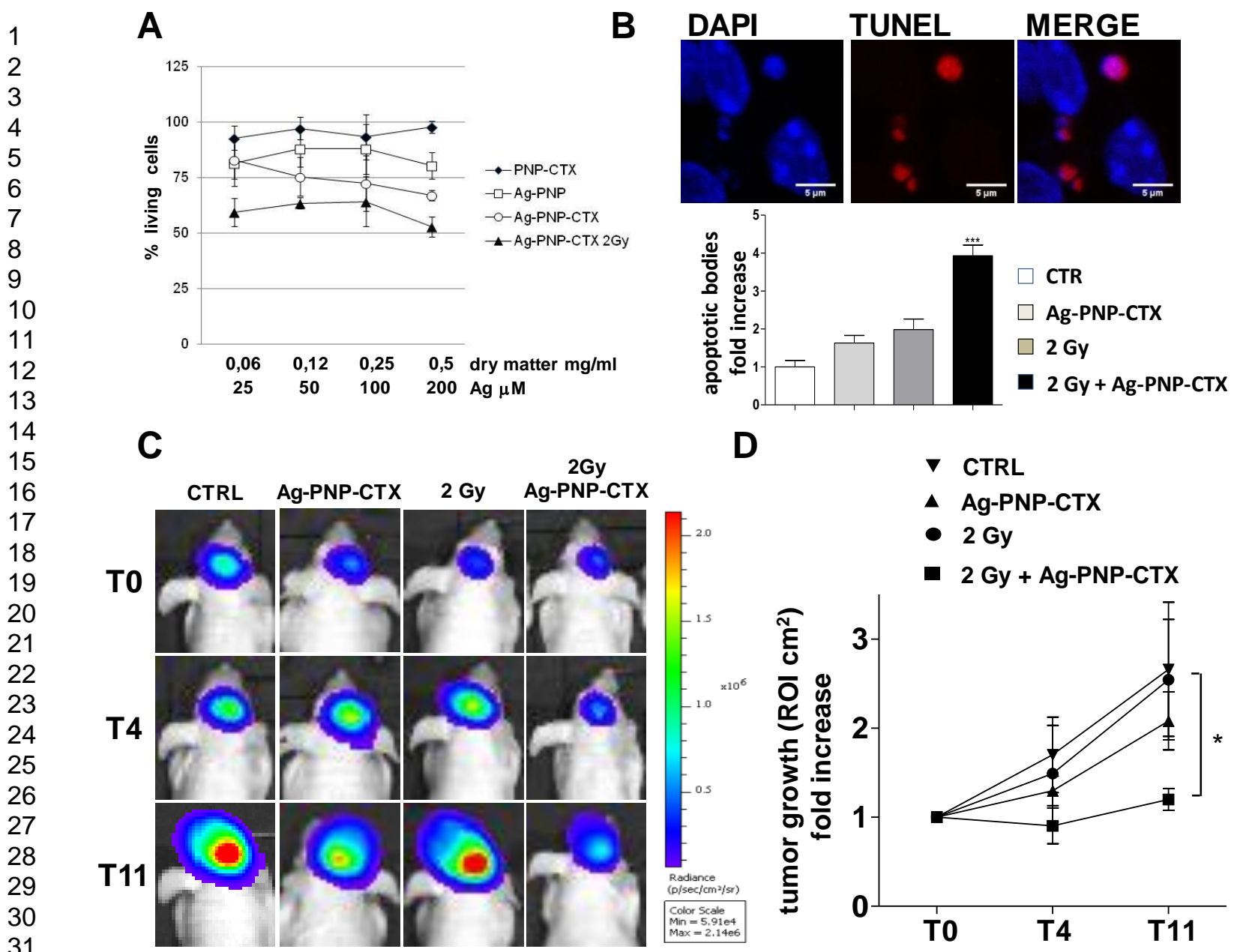

34 Figure 9. Effect of Ag-nps entrapped into PNP-CTX nanovectors on irradiated (2 Gy) and non35 36 irradiated U87MG cells and tumors viability. (A) Upon treatment with the indicated nanoconstructs cell survival fraction was measured by MTT assay. Cells were exposed to increasing concentrations of $\mathrm{Ag}$-nps for 72 hours The obtained relative values were normalized to the values from the 9 corresponding untreated cells and are shown as percentage survival. Results are expressed as mean 0 percentage of 3 independent experiments performed in triplicates SD. (B) In situ detection of 1 apoptosis by DAPI/TUNEL staining and quantification of apoptotic bodies (1-5 $\mu \mathrm{m}$ size) in U87MG 2 cryosections from non-irradiated and irradiated (2 Gy) mice injected with Ag-PNP-CTX nanovectors. Animals were sacrificed 48 hours after nanovector injection. Four mice/experimental group were analyzed. Results are expressed as mean values normalized to CTR values ES. (C) Luciferase imaging of representative mice: untreated (CTRL, 4 mice); injected with Ag-PNP-CTX nanovectors as single agent ( 2 doses of $1 \mathrm{mg} / \mathrm{mouse}$ followed by 2 doses of $0,5 \mathrm{mg} / \mathrm{mouse}$, administration interval: 48-72 hours, 5 mice); irradiated (2 Gy single dose, 6 mice); treated with radiations and concomitant 9 Ag-PNP-CTX nanovectors (6 mice). Treatments started 11 days after U87MGluc2 cell implantation 0 (T0=D11). (D) Tumor growth during 11 days of observation measured by area detected setting 1 automatic ROI (50\%). Results are expressed as mean values normalized to TO values SE. Statistical significance was evaluated by Paired T test. Significance: ${ }^{\star} p<0,05$ 